\title{
INVESTIGAÇÃO SOBRE A SOBREVIVÊNCIA DAS EMPRESAS BENEFICIÁRIAS DE INCENTIVOS FISCAIS NO CEARÁ NO PERÍODO DE 2005 A 2010'
}

\author{
Mauricio Benegas ${ }^{2}$
}

Neste trabalho é estimada a taxa de sobrevivência de empresas localizadas no estado do Ceará e beneficiárias de incentivos fiscais no âmbito do Fundo de Desenvolvimento Industrial (FDI), especificamente no Programa de Incentivo ao Desenvolvimento Industrial (Provin). Para tanto, foi utilizado o estimador não paramétrico de Kaplan-Meier, comparando-se os resultados das empresas beneficiárias com os resultados obtidos para empresas não beneficiárias. Os resultados mostram que a probabilidade de sobrevivência das empresas beneficiárias é superior ao das empresas não beneficiárias, independentemente de localização, setor de atividade ou tamanho da empresa. Com base nas curvas de sobrevivência estimadas, é especificada uma regressão de Cox, em que os resultados sugerem que a efetividade dos benefícios do programa é maior entre as firmas de porte maior.

Palavras-chave: desenvolvimento regional; análise de sobrevivência; benefícios fiscais; FDl; Kaplan-Meier; regressão de Cox.

\section{INVESTIGATION ON THE SURVIVAL OF BENEFICIARY COMPANIES OF TAX INCENTIVES IN CEARÁ FOR THE PERIOD 2005 TO 2010}

This paper estimates the survival rate of companies located in the State of Ceará and beneficiaries of tax incentives under the Industrial Development Fund (FDI), specifically in the Incentive Program for Industrial Development (Provin). Kaplan-Meier non-parametric estimator was used, comparing the results of the beneficiary companies with the results obtained for non-beneficiary companies. The results show that the probability of survival of the beneficiary companies is higher than that of the non-beneficiary companies, regardless of location, activity sector or company size. Based on the estimated survival curves, a Cox regression is specified in which the results suggest that the program benefits effectiveness is higher among larger firms.

Keywords: regional development; survival analysis; tax incentive; FDI; Kaplan-Meier; Cox regression. 


\section{INVESTIGACIÓN SOBRE LA SUPERVIVENCIA DE LAS EMPRESAS BENEFICIARIAS DE INCENTIVOS FISCALES EN EL CEARÁ EN EL PERÍODO DE 2005 A 2010}

En este trabajo se estima la tasa de supervivencia de empresas ubicadas en el estado de Ceará y beneficiarias de incentivos fiscales en el marco del Fondo de Desarrollo Industrial (FDI), específicamente en el Programa de Incentivo al Desarrollo Industrial (Provin). Para ello se utilizó el estimador no paramétrico de Kaplan-Meier, comparándose, los resultados de las empresas beneficiarias con los resultados obtenidos para empresas no beneficiarias. Los resultados muestran que la probabilidad de supervivencia de las empresas beneficiarias es superior al de las empresas no beneficiarias, independientemente de la ubicación, sector de actividad o tamaño de la empresa. Con base en las curvas de supervivencia estimadas se especifica una regresión de Cox en que los resultados sugieren que la efectividad de los beneficios del programa es mayor entre las empresas de mayor tamaño.

Palabras clave: desarrollo regional; análisis de supervivencia; beneficios fiscales; Kaplan-Meier; regresión de Cox.

\section{ENQUÊTE SUR LA SURVIE DES SOCIÉTÉS BÉNÉFICIAIRES DES INCITATIONS FISCALES AU CEARÁ POUR LA PÉRIODE 2005 À 2010}

Ce document a estimé que le taux de survie des entreprises dans l'État de Ceará et les bénéficiaires des incitations fiscales dans le cadre du Fonds de développement industriel (IDE), en particulier Programme d'encouragement pour le développement industriel (Provin). Un estimateur non paramétrique de Kaplan-Meier a été utilisé pour comparer les résultats des entreprises bénéficiaires à ceux obtenus pour des entreprises non bénéficiaires. Les résultats montrent que la probabilité de survie des entreprises bénéficiaires est supérieure à celle des entreprises non bénéficiaires, indépendamment du lieu d'implantation, du secteur d'activité ou de la taille de l'entreprise. Sur la base des courbes de survie estimées, une régression de Cox est spécifiée dans laquelle les résultats suggèrent que l'efficacité des avantages du programme est plus élevée dans les grandes entreprises.

Mots-clés: développement régional; analyse de survie; avantages fiscaux; IDE; Kaplan-Meier; régression de Cox.

JEL: C41; D22; H32; H73; R58. 


\section{INTRODUÇÃO}

Nas últimas décadas, tem sido frequente o uso de benefícios fiscais como instrumento de política econômica. Especificamente com o objetivo de atrair novos investimentos, todas as Unidades Federativas (UFs), em maior ou menor grau, têm recorrido às despesas tributárias, tais como créditos do Imposto sobre Circulação de Mercadorias e Prestação de Serviços (ICMS). De fato, a partir de meados da década de 1990, houve uma intensificação da competição entre os estados por novos investimentos usando tais instrumentos. $\mathrm{O}$ acirramento dessa competição ficou conhecido como guerra fiscal.

Ocorre, porém, que essa não é uma questão recente, tampouco exclusiva dos entes subnacionais, tendo, entretanto, aumentado em face da crescente integração entre os mercados. De acordo com Sousa (2008), desde o fim da Segunda Guerra Mundial, os Estados nacionais passaram a disputar de forma mais intensa os investimentos externos, utilizando como arma políticas de incentivo industrial.

Existe uma vasta literatura que busca justificar a intensificaçáo do uso de incentivos fiscais como política de desenvolvimento. Irffi, Nogueira e Barreto (2009) sugerem que as diferenças estruturais consolidadas ao longo do tempo, assim como a omissão do governo federal para combater as desigualdades regionais, principalmente após a Constituição Federal de 1988 (CF/1988), estimularam as políticas estaduais de incentivo fiscal.

Segundo Sousa (2008), a tentativa de reduzir as desvantagens competitivas existentes entre os estados ou as regióes, tais como deficiências na infraestrutura, baixa qualificação da mão de obra, distância dos centros consumidores ou dos centros produtores dos insumos, é a principal motivação para a utilização das políticas de desenvolvimento industrial.

Sobre o uso de incentivos fiscais no estado do Ceará, Carvalho, Barreto e Oliveira (2007, p. 3) argumentam que

as isenções fiscais e os subsídios na área industrial vêm sendo um dos principais mecanismos utilizados para proporcionar, mesmo que de forma artificial, uma maior dinâmica a nossa economia. Devido à competição das outras unidades da federação e na ausência de atrativos naturais, o governo utiliza esses instrumentos para atrair capitais produtivos de fora para dentro do estado.

Pontes e Vianna (2005) afirmam que tanto a União quanto os estados têm pautado suas políticas de industrialização em dois pilares: i) oferta de infraestrutura física; e ii) incentivo fiscal, sob a forma de isenção ou de diferimento de impostos. Para os autores, entretanto, os estados adotam principalmente a concessão de benefícios fiscais. 
Segundo Amaral Filho (2001), a intensificação da globalização e da abertura econômica, principalmente a partir dos anos 1990, impôs às empresas um elevado nível de competitividade, o que praticamente as obrigou a abandonar os vínculos territoriais e buscar locais nos quais subsídios, disponibilidade de mão de obra barata e facilidades de mercado permitissem uma redução em seus custos. Ao mesmo tempo, o desenvolvimento das telecomunicações e da informática reduziu a necessidade da proximidade física entre a produção e a administração das empresas. Agora, a administração ou a área de pesquisa e desenvolvimento (P\&D) já não precisam estar fisicamente próximas da unidade fabril.

Atualmente, as políticas de atração de investimentos com base em isençôes e subsídios estão disseminadas em praticamente todos os estados da Federação. Mesmo o estado de São Paulo, que tanto critica a concessão de incentivos fiscais, envolveu-se em uma guerra fiscal com o estado de Minas Gerais nos produtos da chamada linha branca, especialmente após a concessão de benefícios municipais e estaduais para instalação de empresas no município mineiro de Extrema. Pontes e Vianna (2005) afirmam que todos os estados brasileiros adotam políticas de incentivos fiscais à industrialização.

As concessóes de benefícios, entretanto, terminam por gerar externalidades negativas, visto que a atração de investimentos para determinada regiáo termina por ocasionar a redução do investimento e da arrecadação em outras regiōes, reduzindo inclusive o montante total da arrecadação nas regiốes envolvidas. De acordo com Oates (1988³ apud Sousa, 2008, p. 13), "a competição tributária entre estados pode causar potencialmente uma reduçấo nas receitas entre eles, pois tende a produzir uma estrutura tributária fortemente regressiva, devido a um esforço fiscal cada vez menor destes". Tem-se também a criação de um verdadeiro círculo vicioso, visto que a concessão de um benefício por uma região praticamente obriga as outras regiōes a concederem benefício semelhante. ${ }^{4}$

No estado do Ceará, os principais benefícios fiscais são concedidos sob a égide do Fundo de Desenvolvimento Industrial (FDI), instituído pela Lei no 10.367, de 7 de dezembro de 1979, especificamente no Programa de Incentivo ao Desenvolvimento Industrial (Provin). Criado com a finalidade de atrair investimentos industriais para o estado e ao mesmo tempo descentralizar o desenvolvimento, o FDI, mesmo depois de mais de trinta anos, permanece como o principal instrumento de atração de empresas para o estado do Ceará.

3. Oates, W.; Schwab, R. Economic competition among jurisdictions: efficiency enhancing or distortion inducing? Journal of Public Economics, n. 35, p. 333-354, 1988.

4. Formalmente, a competição fiscal entre os estados pode ser visto como um jogo não cooperativo em que o equilíbrio de Nash prescreve que os estados devem oferecer benefícios cada vez maiores. No modelo proposto por Wildasin (1988), por exemplo, o autor conclui que em equilíbrio há aumento da alíquota média do imposto sobre consumo e uma redução da oferta de bens públicos, quando se considera o país como um todo. 
Inicialmente, os benefícios do FDI destinavam-se exclusivamente a estabelecimentos industriais, e eram operacionalizados principalmente sob a forma de empréstimos de médio e longo prazo concedidos às empresas industriais através do Banco de Desenvolvimento do Ceará S/A (Bandece). A partir de 2003, a sistemática mudou radicalmente, e o que antes era empréstimo para pagamento de parte do imposto apurado passou a ser um diferimento de parte do saldo devedor do imposto (ICMS) pelo prazo de 36 meses, ressaltando-se que, ao final do período, a regra geral é que retornam aos cofres do estado apenas $25 \%$ dos valores diferidos. Em termos gerais, é esta a sistemática que prevalece até os dias de hoje.

Existe uma discussão ainda em pauta sobre os reais benefícios do uso de competição fiscal para o desenvolvimento regional. Muitos são os que defendem e mais ainda os que criticam. ${ }^{5}$ Entre as inúmeras críticas que cercam o uso de incentivos fiscais, uma das mais frequentes e menos estudadas é a de que firmas que recebem benefícios fiscais permanecem em atividade no estado pelo tempo de duraçáo destes ou pouco mais. Em outros termos, empresas beneficiárias de incentivos fiscais teriam, em tese, uma sobrevida aquém do suficiente para compensar, do ponto de vista social, uma política de renúncia fiscal, por exemplo.

Este trabalho busca investigar essa questão ao menos em parte. Especificamente, o artigo analisa a taxa (ou a probabilidade) de sobrevivência das empresas beneficiárias do FDI/Provin. Para este fim, foi utilizado o conceito de função de sobrevivência, que mede a probabilidade de uma firma sobreviver além de uma data $T$, dado que a mesma firma sobreviveu até a data $T$. A análise empírica é conduzida estimando-se a função de sobrevivência usando o estimador não paramétrico de Kaplan-Meier. O estimador de Kaplan-Meier permite a comparação de curvas de sobrevivência estimadas para diferentes grupos. Com base nos resultados obtidos, uma regressão de Cox é proposta, por meio da qual é estimada a taxa instantânea de falha, utilizando como covariáveis as que mostraram diferenças estatisticamente significativas quanto às curvas de sobrevivência.

No Brasil, um dos mais importantes estudos sobre a análise de sobrevivência de empresas em um contexto geral é o do Serviço Brasileiro de Apoio às Micro e Pequenas Empresas (Sebrae, 2011). De acordo com o estudo, existem dois tipos de metodologias para o cálculo da taxa de sobrevivência de empresas: a verificação in loco para constatar o funcionamento das empresas ou a utilização dos bancos de dados oficiais. A verificação in loco certamente produz dados mais atualizados, visto que o encerramento das atividades nos registros oficiais normalmente ocorre muito depois do encerramento de fato das atividades empresariais. Entretanto, em função de fatores como p tempo e principalmente o custo, assim como em face da disponibilidade das informaçóes, a opção foi pela utilização das bases de dados

5. Varsano (1997) estuda em pormenores os prós e contras da competição fiscal. 
oficiais. Deve ser ressaltado que a utilização dos dados constantes dos bancos de dados oficiais permitiu estudar uma amostra de 726 empresas (194 beneficiárias e 532 não beneficiárias).

A opção pela pesquisa in loco ou pela busca nos dados oficiais pode apresentar resultados diferentes em face do momento que se define como encerramento das atividades da empresa. Neste estudo, foi considerada a data da homologação da baixa a pedido (quando o contribuinte solicita a baixa ou o encerramento) ou da baixa de ofício (quando o Fisco detecta que a empresa já não funciona e cancela sua inscrição no cadastro da Secretaria da Fazenda - Sefaz).

O presente artigo vai comparar a sobrevivência de empresas beneficiárias e não beneficiárias em cinco cenários propostos. No primeiro cenário, as empresas são segmentadas apenas em função do recebimento ou não do benefício. $\mathrm{O}$ segundo cenário considera, no primeiro cenário, a localização espacial das empresas. O terceiro cenário considera, no primeiro cenário, a atividade econômica das empresas. O quarto cenário considera, no primeiro cenário, o nível do faturamento das empresas. Por fim, o quinto cenário considera, no primeiro cenário, o percentual do benefício em relação ao faturamento das empresas beneficiárias. A finalidade da análise de tais cenários é responder às seguintes questóes: i) a sobrevivência das empresas beneficiárias é superior à das empresas não beneficiárias como se supóe?; ii) a localização das empresas impacta na sua sobrevivência?; iii) existe diferença significativa de sobrevivência em função da atividade econômica?; iv) percentuais maiores de benefício impactam nos índices de sobrevivência?; e v) o nível de faturamento impacta a sobrevivência?

Este trabalho não tem a pretensão de questionar a política de incentivos ou propor alternativas, mas apenas contribuir para a compreensão de um programa complexo e importante para o estado.

Ao final do artigo, constatou-se uma sobrevivência das empresas beneficiadas superior à das empresas não beneficiadas em todos os cenários. Ressaltando-se que, de forma geral, os mais baixos índices de sobrevivência foram encontrados para empresas não beneficiadas localizadas em Fortaleza. Também chama atenção a alta mortalidade detectada nos segmentos de empresas têxteis e de confecçáo, ainda quando possuidores de benefícios fiscais. Os resultados obtidos com a regressão de Cox mostram que, muito embora as empresas beneficiadas tenham uma probabilidade de sobrevivência superior, quando uma empresa não beneficiada passa a ter o benefício, a taxa instantânea de falha aumenta em geral, mas diminui entre as empresas de porte maior.

Além desta introdução, o trabalho está organizado da seguinte forma: a seção 2 explica de forma sucinta como funciona o FDI, em especial o Provin; a seção 3 trata da metodologia empregada na pesquisa e do método de coleta de dados; 
a seção 4 apresenta os resultados obtidos nos diversos cenários em que os dados foram segmentados; por fim, a seção 5 contém as principais conclusōes do trabalho.

\section{FUNDO DE DESENVOLVIMENTO INDUSTRIAL}

O FDI foi criado em 1979, pela Lei no 10.367 , durante o segundo governo de Virgílio Távora, com o objetivo de promover o desenvolvimento das atividades industriais em todo o território do Ceará. Ainda hoje, o FDI é o principal instrumento utilizado por esse estado para captação de novas empresas e ampliação das já existentes.

No âmbito do FDI, existem diversos programas: o Provin, objeto do presente estudo; o Programa de Incentivo às Atividades Portuárias e Industriais do Ceará (Proapi); o Programa de Incentivo à Industrialização de Produtos para Exportaçáo no Estado do Ceará (Proinex); o Programa de Desenvolvimento no Comércio Internacional e das Atividades Portuárias e Aeroportuárias (PDCI); o Programa de Centrais de Distribuição de Mercadorias (PCDM); o Programa de Atração de Empreendimentos Estratégicos (Proade); o Programa de Desenvolvimento da Cadeia Produtiva Geradora de Energia Eólica (Pró-eólica); entre outros.

Inicialmente, o principal benefício concedido pelo FDI/Provin era o financiamento subsidiado de parte do ICMS apurado mensalmente pelas empresas beneficiadas. $\mathrm{O}$ mecanismo fazia que fossem contabilizadas como receitas do Tesouro valores que na realidade não ingressavam nos cofres públicos. De forma simplificada, o procedimento era o seguinte: apurado o saldo devedor do imposto (débitos/créditos), a empresa preparava a guia de recolhimento e a apresentava ao agente financeiro (inicialmente o Bandece), ocasiáo em que era feito um empréstimo de parte do valor do imposto apurado. Ao fim de um período de três anos, a empresa, atendidas algumas condições, pagava apenas parte do valor financiado. Ou seja, quanto mais produzissem, maior o benefício concedido sob a forma de empréstimo.

Em 2003, por meio da Lei no 13.377 , o estado alterou a sistemática do incentivo, substituindo a modalidade de empréstimo pelo diferimento de parte do imposto apurado. A mudança permitiu que deixassem de ser contabilizados como receita do estado valores que na realidade não ingressavam em seus cofres, adequando, dessa forma, transferências a municípios e aplicaçóes compulsórias em saúde e educação aos montantes que efetivamente ingressavam no Tesouro estadual. Estabelecia o art. 2o da norma que "por ocasiāo da apuração mensal do imposto, passará a deduzir do saldo devedor apurado o valor correspondente ao que seria o da parcela líquida do empréstimo, valor esse que fica diferido" (Ceará, 2003). Também ao final de três anos, atendidas algumas condiçóes, apenas parte do 
imposto diferido seria efetivamente recolhido aos cofres do estado. Tal sistemática perdura até hoje, e é ela que será objeto deste estudo.

O percentual do imposto diferido, assim como o percentual desse montante que será efetivamente recolhido aos cofres do estado ao final do período de 36 meses (retorno), dependia inicialmente (Decreto no 27.040/2003) do volume de investimento, do setor de atividade, da quantidade de empregos, do impacto sobre a demanda por matérias-primas, de insumos e serviços locais, da localizaçấo da empresa, entre outros. Em 2008 (Decreto no 29.183), a forma de cálculo do prazo, do percentual do benefício e de seu retorno passou a considerar o número de empregos, o montante de operaçóes interestaduais e com o exterior, a localização do empreendimento (distância em relação à Fortaleza e produto interno bruto PIB do município) e, ainda, a responsabilidade social, cultural e ambiental, como pode ser observado no anexo I do Decreto no 29.183/2008.

A regra geral (existem exceçôes) prevê um diferimento máximo de $75 \%$ e um retorno, atendidas algumas condições, de no máximo $25 \%$ do valor diferido ao final de 36 meses.

\section{METODOLOGIA}

\subsection{Análise de sobrevivência}

Usualmente, a análise de sobrevivência é empregada em análises clínicas, tais como avaliaçáo de uma nova droga ou de um novo tratamento. Entretanto, tem também sido empregada na engenharia, para o estudo da vida útil de máquinas; na sociologia, para o estudo de tempo entre eventos (liberação de presos e ocorrência de crimes); na demografia (mortes, casamentos) (Colosimo e Giolo, 2006). Na economia, tem também sido usada para a análise da sobrevivência empresarial.

Em Kleibaum (1985 apud Almawi, 2009, p. 53), a análise de sobrevivência é definida como um conjunto de procedimentos estatísticos nos quais a variável dependente é o tempo necessário para a observação do evento de interesse (tempo de falha). O conceito central é a função de sobrevivência como a probabilidade de uma observação não falhar até certo tempo $t$, ou seja, a probabilidade de uma observaçáo sobreviver ao tempo $t$. Formalmente tem-se $S(t)=\operatorname{Pr}[T \geq t]$, em que $S$ é a probabilidade de sobrevida, $t$ é o tempo de sobrevida e $T$ é o tempo de falha (evento de interesse).

Nunes e Sarmento (2010) explicam a função sobrevivência como a probabilidade de uma empresa sobreviver além de um determinado período $t$, dado que

6. Kleinbaum, D. Survival Analysis: a self-learning text. New York: Springer-Verlag, 1995. 
sobreviveu até esse período. Esclarecem ainda que a função sobrevivência tem valor igual a 1 no momento inicial, tendendo a 0 à medida que o tempo passa.

A grande limitação do estudo da sobrevivência é a existência de interrupçóes das observações antes que se verifique a ocorrência do evento de interesse (falha). Ou seja, têm-se, em muitas situaçóes, apenas observaçóes parciais de algumas das respostas, o que é denominado censura. Isso acontece quando, por exemplo, o acompanhamento da empresa foi interrompido ou quando a empresa muda de localidade, interrompendo o estudo. Tem-se censura também quando o estudo termina, e o evento de interesse ainda náo foi observado. De acordo com Kleibaum (1985 apud Almawi, 2009, p. 54), tem-se censura quando, apesar de existirem informaçóes sobre um indivíduo, não sabemos quando o evento falha ocorreu. A ausência da totalidade das informaçôes inviabiliza a utilização de técnicas estatísticas clássicas de análise de variância (Colosimo e Giolo, 2006).

No presente estudo a função sobrevivência foi definida como o tempo até que a empresa seja baixada de ofício ou baixada a pedido no cadastro da Secretaria da Fazenda do Estado do Ceará (Sefaz/CE). A ocorrência de qualquer dessas situaçóes caracteriza a falha, que é o evento de interesse. Considerou-se a data da primeira das ocorrências a partir de $1^{\circ}$ de janeiro de 2005 , ainda que a empresa tenha sido posteriormente reativada. Neste artigo, tem-se censura quando a empresa permanece ativa após os seis anos de observação (2005-2010). Nestes casos, verifica-se a presença de censura à direita, que Colosimo e Giolo (2006, p. 9) definem como sendo a censura observada nos casos em que o tempo de sobrevivência ultrapassa o tempo de observação. Tem-se censura à direita para todas as empresas que permanecem ativas após 31 de dezembro de 2010.

De acordo com Kleibaum (1985 apud Almawi, 2009, p. 75), a função sobrevivência pode ser obtida através de alguns modelos e ferramentas, entre as quais se destacam o modelo de Cox e o estimador de Kaplan-Meier.

O estimador de Kaplan-Meier ou produto-limite, de acordo com Colosimo e Giolo (2006), é um estimador não paramétrico utilizado para estimar a função sobrevivência, sendo uma adaptação da função de sobrevivência empírica, que, na ausência de censuras, é definida simplesmente como:

$$
\hat{S}(t)=\frac{\mathrm{n}^{\mathrm{o}} \text { de observações que não falharam até o tempo } t}{\mathrm{n}^{\mathrm{o}} \text { total de observações no estudo }} .
$$

Quando se considera a existência de censuras, a expressão geral do estimador de Kaplan-Meier para um dado tempo té:

$$
\hat{S}\left(t_{j}\right)=\prod_{j: t_{j}<t} \frac{n_{j}-d_{j}}{n_{j}} .
$$


Em que:

- $t_{1}<t_{2}<\cdots<t_{k}$ são os $k$ tempos distintos e ordenados de falhas;

- $d_{t}=$ número de falhas em $t_{j}, j=1,2, \ldots, t$, e

- $n_{t}=$ número de indivíduos sob risco em $t_{j}$ (indivíduos que não falharam e não foram censurados até o momento imediatamente anterior a $t_{j}$ ).

Conforme pode ser observado, o estimador de Kaplan-Meier para um dado tempo té o produto das relaçóes entre o número de sobreviventes em cada período e o número de indivíduos em risco (observações no início do período).

\subsection{Coleta de dados}

Foram coletados dados de empresas beneficiárias e não beneficiárias do FDI/Provin diretamente dos sistemas Declaração de Informaçóes Econômico-Fiscais (Dief) e do Sistema Cadastro, ambos da Sefaz/CE, utilizando-se o software Infoviews, de gerenciamento de banco de dados. As informaçóes coletadas foram confrontadas com informações oriundas do órgão gestor do FDI e do Conselho Estadual de Desenvolvimento Econômico (Cede), visando excluir inconsistências eventualmente existentes nos referidos sistemas.

Inicialmente, selecionaram-se as empresas enquadradas no regime normal de recolhimento (sistemática de débito e crédito) cujas atividades iniciaram-se antes de $1^{\circ}$ de janeiro de 2005, com benefícios já vigentes naquela data e que declararam pelo menos um mês com benefício do FDI/Provin nos exercícios de 2005 a 2010. Da amostra inicialmente selecionada, foram excluídas as empresas que em algum momento no período 2005-2010 mudaram de regime de recolhimento (normalmente para o Simples). Este é o grupo exposto ao fator de interesse: empresas beneficiárias do FDI/Provin.

Para compor o grupo não exposto ao fator de interesse, foram selecionadas empresas não beneficiadas pelo FDI/Provin com o mesmo Código de Atividade Econômica (CNAE) das empresas beneficiadas, desde que enquadradas no regime normal de recolhimento, cujas atividades iniciaram-se antes de $1^{\circ}$ de janeiro de 2005 , com faturamento superior a $\mathrm{R} \$ 95.169,60$ no exercício de 2005 (limite máximo de faturamento para enquadramento como microempresa no exercício de 2005$)^{7}$ e que também não tiveram alteração de regime de recolhimento no período $2005-2010$. $^{8}$

7. 0 Decreto ํㅡ 27.070, de 28 de maio de 2003, do estado do Ceará, estabelece 48.000 Ufirces como limite de faturamento para enquadramento como microempresas. A Instrução Normativa no 40/2004, de 30 de dezembro de 2004, da Sefaz/CE fixou o valor da Ufirce para o exercício de 2005 em R \$1,9827, o que faz com que o faturamento máximo para que uma empresa possa ser enquadrada como microempresa no estado do Ceará fosse R\$95.169,60 naquele exercício. 8. 0 faturamento utilizado neste trabalho corresponde às saídas registradas em notas fiscais emitidas diariamente. A série obtida foi deflacionada utilizando o deflator implícito do setor industrial tendo como data base janeiro de 2005. O deflator foi obtido do Sistema de Contas Nacionais do Instituto Brasileiro de Geografia e Estatística (SCN/IBGE). 
GRÁFICO 1

Distribuição espacial das empresas beneficiadas e não beneficiadas

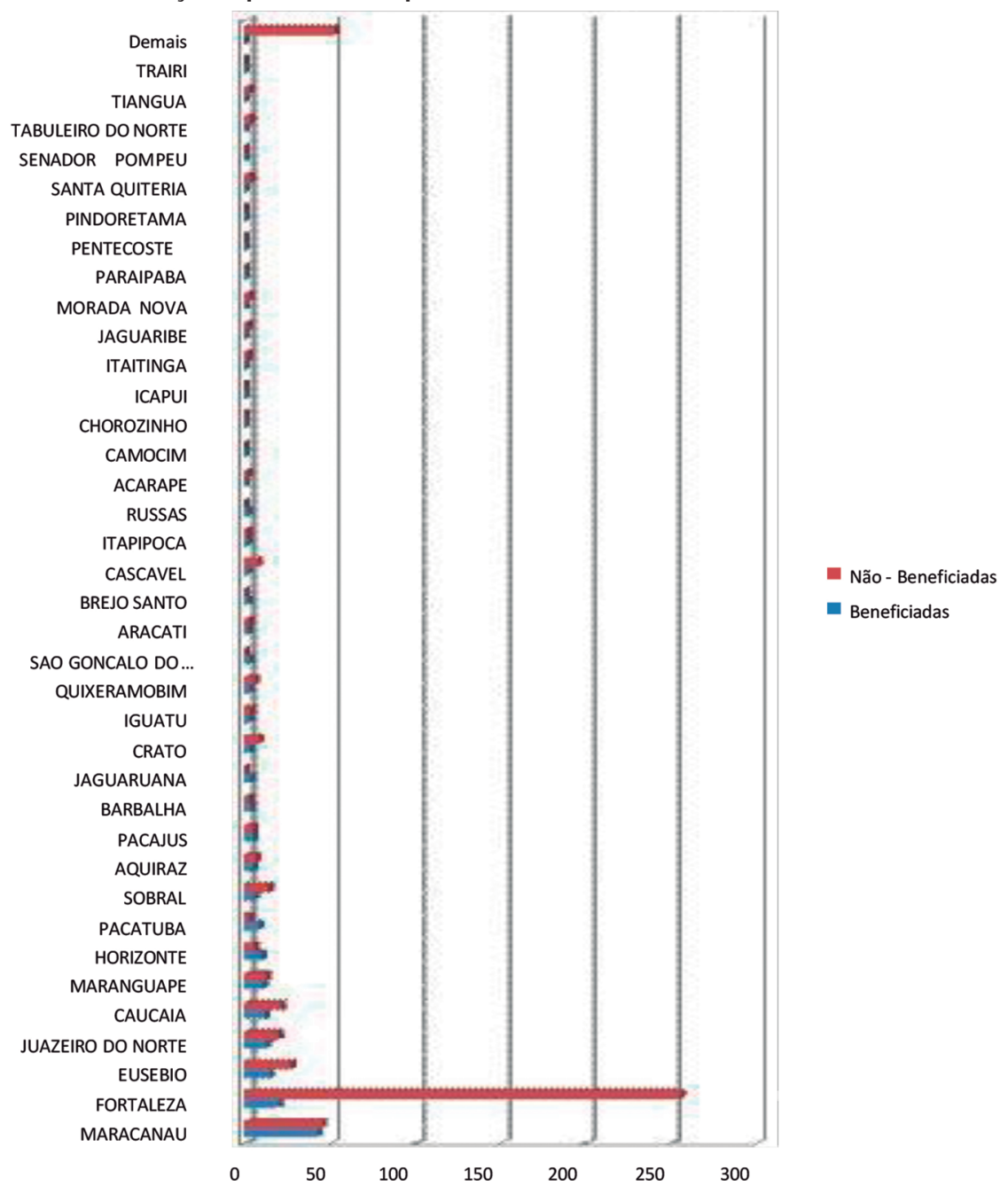

Elaboração e estimativas do autor.

Obs.: Figura reproduzida em baixa resolução e cujos leiaute e textos não puderam ser padronizados e revisados em virtude das condições técnicas dos originais (nota do Editorial).

\subsection{Base de dados}

A base de dados do presente estudo é composta de 726 empresas, sendo 194 empresas beneficiárias do FDI/Provin e 532 empresas não beneficiadas, todas localizadas no Ceará e inscritas no cadastro da Sefaz. As empresas beneficiadas estão localizadas em 37 municípios e atuam em 91 atividades diferentes (CNAES). As empresas não beneficiadas estão localizadas em sessenta municípios e atuam em 63 atividades diferentes (CNAES). 
No que concerne ao faturamento, há uma grande dispersão dos dados, mesmo considerando-se apenas as empresas beneficiadas, visto que se tem segmentos econômicos ${ }^{9}$ com receita total (2005-2010) variando de R \$ 1,870 milhão (fabricação de veículos, automóveis e carrocerias) até R \$ 19,909 milhóes (indústria de curtimento e calçados), conforme pode ser observado no gráfico 2 .

\section{GRÁFICO 2}

Receita das empresas beneficiadas e não beneficiadas, por segmento econômico (2005-2010)

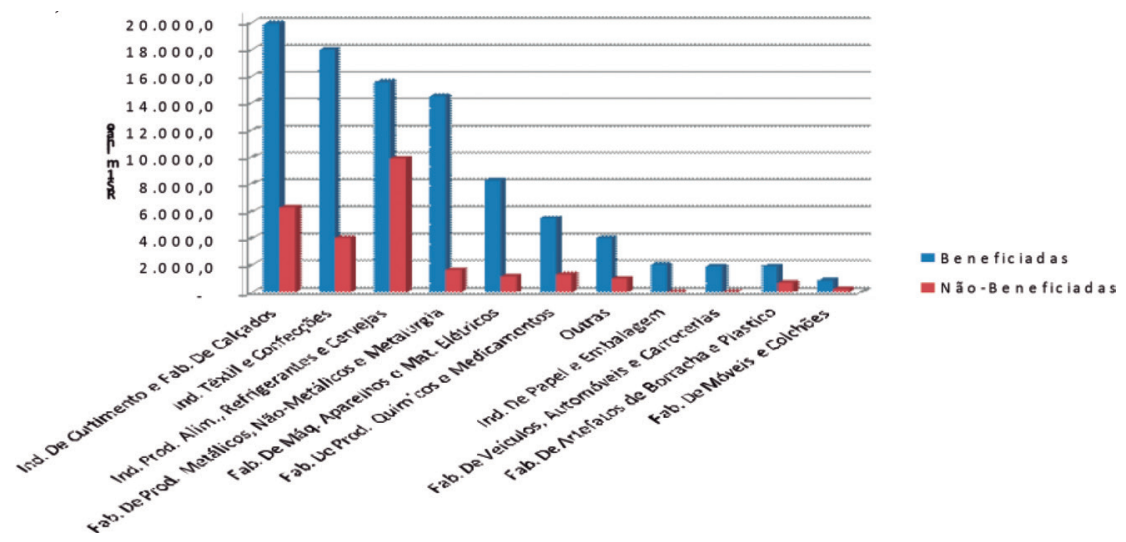

Elaboração e estimativas do autor.

Obs.: Figura cujos leiaute e textos não puderam ser padronizados e revisados em virtude das condições técnicas dos originais (nota do Editorial).

A tabela 1 apresenta um conjunto de estatísticas descritivas sobre as variáveis utilizadas no estudo.

\section{TABELA 1}

\section{Estatísticas descritivas da amostra}

\begin{tabular}{lccc}
\hline & Benefício (FDI) & Local & Receita (R\$) \\
\hline Média & 0,27 & 0,75 & $163.355 .503,31$ \\
Desvio-padrão & 0,44 & 0,44 & $602.227 .694,85$ \\
Mínimo & 0,00 & 0,00 & $118.721,80$ \\
Máximo & 1,00 & 1,00 & $9.218 .321 .855,00$ \\
10 quartil & 0,00 & 0,00 & $2.232 .388,21$ \\
2ọ quartil & 0,00 & 1,00 & $15.210 .585,57$ \\
3ํquartil & 1,00 & 1,00 & $66.690 .350,50$ \\
\hline
\end{tabular}

Elaboração e estimativas do autor.

9. Classificação utilizada na elaboração do cenário 4. 
Como pode ser observado da tabela $1,27 \%$ da amostra recebem benefício do FDI e 75\% estão localizadas na Região Metropolitana (RM) de Fortaleza. Por seu turno, como foi dito anteriormente, a receita apresenta grande dispersão entre as empresas estudadas. Este fato é evidenciado pelo desvio-padrão, que é maior que a receita média quase quatro vezes. Essa dispersão reflete, de fato, duas importantes características do setor industrial no Ceará. Primeiro seu tamanho. Considerando-se 2010 como ano-base, a participação da indústria no PIB do Ceará era de 21,9\% ante $27,4 \%$ no cenário nacional (Ceará, 2016). A segunda característica relevante do setor industrial no estado é a concentração. Como pode ser visto na tabela 2 , os setores de alimentos, têxtil e de calçados respondem por quase metade de toda a receita entre as empresas na amostra, $46,7 \%$.

A tabela 2 também reporta algumas estatísticas que informam aspectos sobre a distribuição de receita, do número de firmas e de como estão distribuídos os recursos do FDI entre os setores estudados. As quatro primeiras colunas da tabela mostram a distribuição dos valores absolutos e relativos do número de empresas e da receita em cada setor estudado.

Note-se que, assim como foi constatado quanto à receita, existe também uma grande concentração no número de empresas em poucos setores. Especificamente os setores têxtil e de vestuário respondem por $45,5 \%$ do número de empresas na amostra estudada.

A distribuição dos recursos do FDI parece acompanhar essa concentração, seja no número de empresas seja na receita. Como já foi dito, considerando-se a amostra toda, $27 \%$ das empresas recebem algum benefício do FDI. Deste percentual, 8,3\% está concentrado nos setores de alimentos, têxtil e de calçados, ou seja, mais de um terço dos benefícios do FDI se destina a três setores entre os estudados neste trabalho, os quais, como se viu, concentram quase metade das empresas.

Sob a ótica da receita, os resultados são qualitativamente semelhantes quanto à concentração dos benefícios. Por inspeção das duas últimas colunas da tabela 2, conclui-se que, entre as empresas beneficiadas, os setores de alimentos, têxtil, vestuário e calçados concentram $16,2 \%$ da receita total da amostra estudada. Esses resultados sugerem que, em sua extensão, houve uma concentração dos benefícios do FDI e essa concentração simplesmente acompanhou a estrutura da indústria cearense. 
TABELA 2

Análise descritiva sobre a distribuição dos benefícios do FDI

\begin{tabular}{|c|c|c|c|c|c|c|c|c|}
\hline & \multirow{2}{*}{$\begin{array}{l}\text { Número de } \\
\text { firmas }\end{array}$} & \multirow{2}{*}{$\begin{array}{c}\text { Firmas } \\
(\%)\end{array}$} & \multirow{2}{*}{$\begin{array}{l}\text { Receita } \\
\text { (R\$) }\end{array}$} & \multirow{2}{*}{$\begin{array}{l}\text { Receita } \\
(\%)\end{array}$} & \multicolumn{2}{|c|}{$\begin{array}{l}\text { Distribuição do FDI por } \\
\text { número de firmas }\end{array}$} & \multicolumn{2}{|c|}{$\begin{array}{l}\text { Distribuição do FDI } \\
\text { por receita }\end{array}$} \\
\hline & & & & & $\begin{array}{l}\text { Recebe } \\
(\%)\end{array}$ & $\begin{array}{l}\text { Não recebe } \\
(\%)\end{array}$ & $\begin{array}{l}\text { Recebe } \\
(\%)\end{array}$ & $\begin{array}{c}\text { Não recebe } \\
(\%)\end{array}$ \\
\hline Alimentos & 126 & 17,4 & $14.893 .545,39$ & 12,6 & 2,5 & 14,9 & 7,5 & 5,0 \\
\hline Bebidas & 14 & 1,9 & $10.566 .275,23$ & 8,9 & 0,6 & 1,4 & 0,8 & 8,1 \\
\hline Têxtil & 47 & 6,5 & $14.177 .455,76$ & 12,0 & 3,0 & 3,4 & 0,9 & 11,1 \\
\hline Vestuário & 204 & 28,1 & $7.820 .487,68$ & 6,6 & 2,8 & 25,3 & 2,5 & 4,1 \\
\hline Couro e calçados & 66 & 9,1 & $26.169 .731,08$ & 22,1 & 3,4 & 5,6 & 5,3 & 16,8 \\
\hline Papel e celulose & 21 & 2,9 & $2.227 .980,45$ & 1,9 & 1,8 & 1,1 & 0,2 & 1,7 \\
\hline Impressão & 1 & 0,1 & $45.057,64$ & 0,0 & 0,1 & 0,0 & 0,0 & 0,0 \\
\hline Produtos químicos & 40 & 5,5 & $5.283 .100,95$ & 4,5 & 1,8 & 3,7 & 1,0 & 3,4 \\
\hline Produtos farmacêuticos & 6 & 0,8 & $1.438 .910,54$ & 1,2 & 0,4 & 0,4 & 0,1 & 1,2 \\
\hline Borracha e plástico & 35 & 4,8 & $2.569 .340,87$ & 2,2 & 2,2 & 2,6 & 0,6 & 1,6 \\
\hline Minerais não metálicos & 41 & 5,6 & $4.443 .981,58$ & 3,7 & 1,5 & 4,1 & 1,0 & 2,8 \\
\hline Metalurgia & 5 & 0,7 & $8.315 .170,35$ & 7,0 & 0,6 & 0,1 & 0,1 & 6,9 \\
\hline Siderurgia & 27 & 3,7 & $3.370 .656,12$ & 2,8 & 1,4 & 2,3 & 0,2 & 2,6 \\
\hline $\begin{array}{l}\text { Máquinas, aparelhos e } \\
\text { materiais elétricos }\end{array}$ & 13 & 1,8 & $8.965 .569,14$ & 7,6 & 0,7 & 1,1 & 0,9 & 6,6 \\
\hline $\begin{array}{l}\text { Máquinas e } \\
\text { equipamentos }\end{array}$ & 11 & 1,5 & $428.092,06$ & 0,4 & 0,6 & 1,0 & 0,0 & 0,3 \\
\hline Veículos & 7 & 1,0 & $1.582 .871,89$ & 1,3 & 0,6 & 0,4 & 0,0 & 1,3 \\
\hline $\begin{array}{l}\text { Transporte (exceto } \\
\text { veículos) }\end{array}$ & 3 & 0,4 & $302.099,28$ & 0,3 & 0,3 & 0,1 & 0,0 & 0,2 \\
\hline Móveis & 25 & 3,4 & $1.083 .403,42$ & 0,9 & 1,0 & 2,5 & 0,2 & 0,7 \\
\hline Diversos & 8 & 1,1 & $349.739,78$ & 0,3 & 0,6 & 0,6 & 0,2 & 0,1 \\
\hline Energia & 14 & 1,9 & $4.208 .932,75$ & 3,5 & 0,6 & 1,4 & 0,5 & 3,1 \\
\hline $\begin{array}{l}\text { Coleta e tratamento de } \\
\text { resíduos }\end{array}$ & 5 & 0,7 & $46.043,75$ & 0,0 & 0,3 & 0,4 & 0,0 & 0,0 \\
\hline $\begin{array}{l}\text { Edificação e } \\
\text { paisagismo }\end{array}$ & 7 & 1,0 & $307.649,70$ & 0,3 & 0,3 & 0,7 & 0,2 & 0,1 \\
\hline
\end{tabular}

Elaboração e estimativas do autor.

\section{RESULTADOS: ESTIMATIVAS DAS CURVAS DE SOBREVIVÊNCIA}

Os resultados das pesquisas sobre a sobrevivência das empresas beneficiárias de incentivos fiscais no âmbito do FDI/Provin foram agrupados em diferentes cenários, a maior parte confrontando empresas beneficiárias com empresas não beneficiárias em função da localização, do tipo de atividade econômica, do CNAE, da receita e do percentual do benefício sobre a receita total, como pode ser visto a seguir. 


\subsection{Cenário 1: empresas beneficiadas versus não beneficiadas}

Inicialmente, foi calculada a sobrevivência das empresas beneficiadas e não beneficiadas do programa FDI/Provin, sem qualquer delimitação. Constatou-se uma sobrevivência ao final de seis anos de $88,7 \%$ das empresas beneficiadas, enquanto a sobrevivência das empresas não beneficiadas ao fim do período de análise foi de apenas $61,8 \%$, conforme se pode observar no gráfico 3 e na tabela 3 .

Provavelmente, a redução da carga tributária e consequentemente uma estrutura de custos mais competitivos são responsáveis pela maior sobrevivência das empresas beneficiadas. Não pode também ser ignorado o fato de que as exigências para concessão do benefício, como a apresentação de projeto e a regularidade fiscal, terminam por triar as empresas com menor nível de organização e consequentemente com menores possibilidades de sobrevivência.

Conforme pode ser observado na tabela 3, desde o primeiro ano, a sobrevivência das empresas beneficiadas é nitidamente superior a das empresas não beneficiadas. Ao final do primeiro ano do estudo (365 dias), apenas $0,5 \%$ das empresas beneficiadas tinha encerrado suas atividades, enquanto no grupo das não beneficiadas esse percentual já foi de $2,1 \%$. Apenas entre os anos três e quatro, cerca de $20 \%$ das empresas não beneficiadas encerrou suas atividades. Ao final dos seis anos de observaçáo, as empresas beneficiadas apresentaram uma probabilidade de sobrevivência estimada 43,5\% maior relativamente às empresas que não receberam benefícios do FDI.

\section{GRÁFICO 3}

Sobrevivência de empresas beneficiadas e não beneficiadas

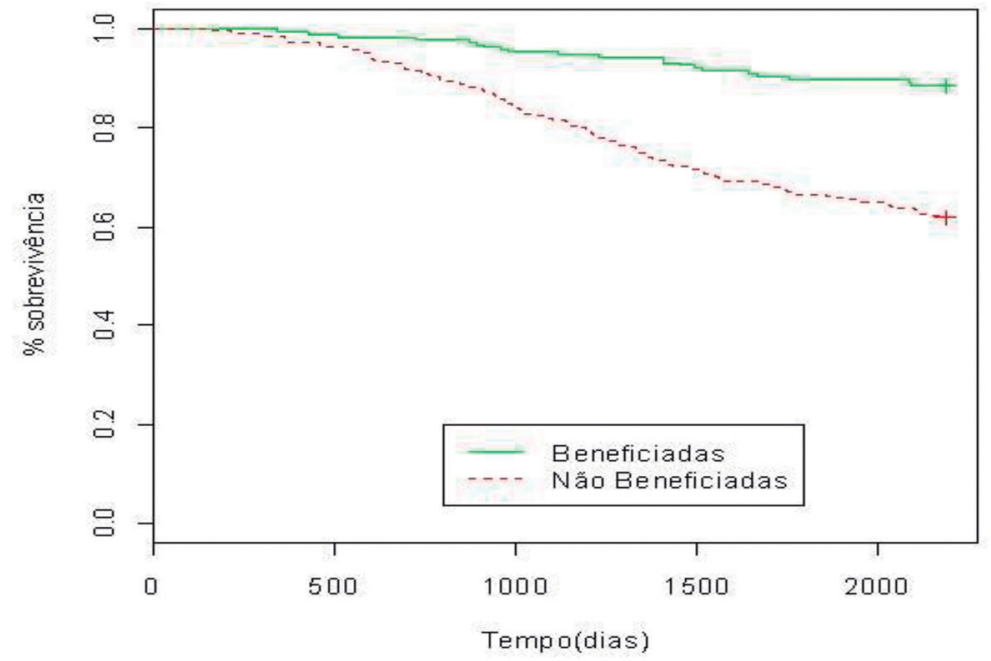


TABELA 3

Sumário das curvas de sobrevivência estimadas: cenário 1

\begin{tabular}{lccc}
\hline \multirow{2}{*}{$\begin{array}{l}\text { Tempo } \\
\text { (dias) }\end{array}$} & \multicolumn{2}{c}{ Sobrevivência } & Diferença entre beneficiários versus não beneficiários (\%) \\
\cline { 2 - 3 } & Beneficiários & Não beneficiários & \\
\hline 0 & 1,000 & 1,000 & 0,0 \\
365 & 0,995 & 0,979 & 1,6 \\
730 & 0,979 & 0,917 & 6,8 \\
1.095 & 0,954 & 0,820 & 16,3 \\
1.460 & 0,928 & 0,722 & 28,5 \\
1.825 & 0,897 & 0,665 & 34,9 \\
2.190 & 0,887 & 0,618 & 43,5 \\
\hline
\end{tabular}

Teste Peto-Peto: Est. $\chi^{2}=44,6$ ( $\left.1 \mathrm{gl}\right)$; Valor $p=2.44 \mathrm{e}-11$

Elaboração e estimativas do autor.

\subsection{Cenário 2: empresas beneficiadas da RM de Fortaleza versus empresas beneficiadas do interior versus empresas não beneficiadas da RM de Fortaleza versus empresas não beneficiadas do interior}

No cenário 2 (gráfico 4 e tabela 4), também se considerou a localização das empresas, mas agora segmentando-se entre RM de Fortaleza (composta por quinze municípios) ou interior do estado. Observou-se que o nível mais elevado de sobrevivência agora foi das empresas beneficiadas e localizadas no interior do estado (sobrevivência de 93,1\% ao final do sexto ano), enquanto o nível mais baixo de sobrevivência é o das empresas não beneficiadas e localizadas na RM de Fortaleza (sobrevivência de 56,9\% ao final do sexto ano). Pode-se constatar que, até o final do terceiro ano, não tinha havido nenhuma baixa no grupo das empresas beneficiadas e localizadas no interior do estado.

Assim como observado no cenário 1 , as empresas não beneficiadas e localizadas na RM de Fortaleza têm o maior índice de mortalidade, talvez confirmando a dificuldade de competirem com um grande número de empresas e com empresas que possuem melhor estrutura de custos. De fato, como mostrado em Mourao (2017), em ambientes competitivos, o tamanho e a idade são fundamentais para a sobrevivência das empresas. Especificamente firmas que estão estabelecidas há mais tempo no mercado e que experimentaram um razoável crescimento, sobretudo dos seus ativos, em geral sobrevivem por mais tempo. Note que, ao final do terceiro ano, verifica-se uma mortalidade superior a $20 \%$ neste grupo de empresas, o que corrobora com essa ideia. 
O resultado foi coerente com o encontrado no cenário 1 para as empresas não beneficiadas (maior mortalidade na RM de Fortaleza), mas diferente no que concerne às empresas beneficiadas, visto que agora o melhor resultado foi obtido pelas empresas localizadas no interior do estado. Este resultado parece estar relacionado com o grande número de empresas dos setores têxtil e de confecçáo, localizadas na RM de Fortaleza - 35 das 41 beneficiadas estão domiciliadas na RM de Fortaleza e 186 das 209 não beneficiadas estão localizadas na RM de Fortaleza.

Por fim, vale destacar que, considerando o pior e o melhor cenário, notam-se diferenças significativas entre as taxas de sobrevivência estimadas. No cenário ora analisado, o pior resultado foi o das empresas não beneficiadas localizadas na RM de Fortaleza e o melhor ficou por conta das empresas beneficiadas localizadas no interior do estado. A última coluna da tabela 4 mostra que, no final do período analisado, as empresas beneficiadas localizadas no interior tiveram probabilidade de sobrevivência estimada $63,6 \%$ maior do que as empresas não beneficiadas localizadas na RM de Fortaleza.

GRÁFICO 4

Sobrevivência de empresas beneficiadas e não beneficiadas - RM de Fortaleza e interior do estado

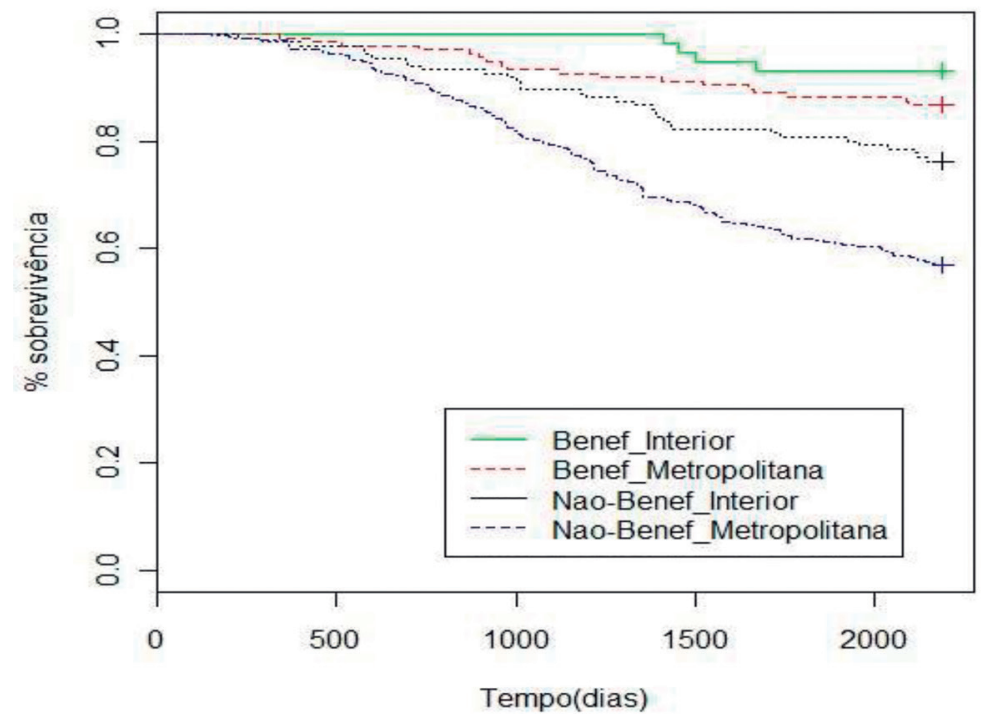

Elaboração e estimativas do autor.

Obs.: Figura reproduzida em baixa resolução e cujos leiaute e textos não puderam ser padronizados e revisados em virtude das condições técnicas dos originais (nota do Editorial). 
TABELA 4

Sumário das curvas de sobrevivência estimadas: cenário 2

\begin{tabular}{|c|c|c|c|c|c|}
\hline \multirow{3}{*}{$\begin{array}{l}\text { Tempo } \\
\text { (dias) }\end{array}$} & \multicolumn{4}{|c|}{ Sobrevivência } & \multirow{3}{*}{$\begin{array}{c}\text { Diferença entre (c) } \\
\text { versus (b) } \\
(\%)\end{array}$} \\
\hline & \multicolumn{2}{|c|}{ RM de Fortaleza } & \multicolumn{2}{|c|}{ Interior } & \\
\hline & Beneficiários (a) & Não beneficiários (b) & Beneficiários (c) & Não beneficiários (d) & \\
\hline 0 & 1,0000 & 1,0000 & 1,0000 & 1,0000 & 0,0 \\
\hline 365 & 0,9930 & 0,9770 & 1,0000 & 0,9850 & 2,4 \\
\hline 730 & 0,9710 & 0,9090 & 1,0000 & 0,9410 & 10,0 \\
\hline 1.095 & 0,9340 & 0,7930 & 1,0000 & 0,8960 & 26,1 \\
\hline 1.460 & 0,9120 & 0,6880 & 0,9660 & 0,8220 & 40,4 \\
\hline 1.825 & 0,8820 & 0,6170 & 0,9310 & 0,8070 & 50,9 \\
\hline 2190 & 0,8680 & 0,5690 & 0,9310 & 0,7630 & 63,6 \\
\hline
\end{tabular}

Teste Peto-Peto: Est. $\chi 2=63,2$ (3 gl); Valor $p=2.44 \mathrm{e}-11$

Elaboração e estimativas do autor.

\subsection{Cenário 3: empresas beneficiadas e não beneficiadas por atividade econômica}

O gráfico 5 mostra as curvas de sobrevivência das empresas beneficiadas e não beneficiadas dos dois grupos de atividade com maior relevância econômica (curtimento e calçados e têxtil), entendendo-se por maior relevância a receita total das empresas beneficiadas durante o período do estudo (2005-2010). Novamente, verifica-se que as empresas beneficiadas têm sobrevivência bem superior às empresas não beneficiadas. Considerando-se as empresas no mesmo setor, ao final do período, as empresas beneficiadas apresentaram uma taxa de sobrevivência de 93,6\%, um número quase $67 \%$ maior do que a taxa de sobrevivência estimada para as empresas do setor que não receberam o benefício.

Por fim, comparando-se empresas beneficiadas nos setores têxtil ou de calçados com as empresas não beneficiadas e pertencentes a outros setores a diferença, ainda em favor das empresas beneficiadas, é um pouco menor. De fato, como pode ser constatada na última coluna da tabela 5, essa diferença foi de 49,28\%. Esses números sugerem que pertencer ao setor têxtil ou de calçados, reduz a taxa de sobrevivência quando essas empresas não possuem benefícios fiscais. 
GRÁFICO 5

Sobrevivência das empresas dos setores de curtimento e calçados e têxtil

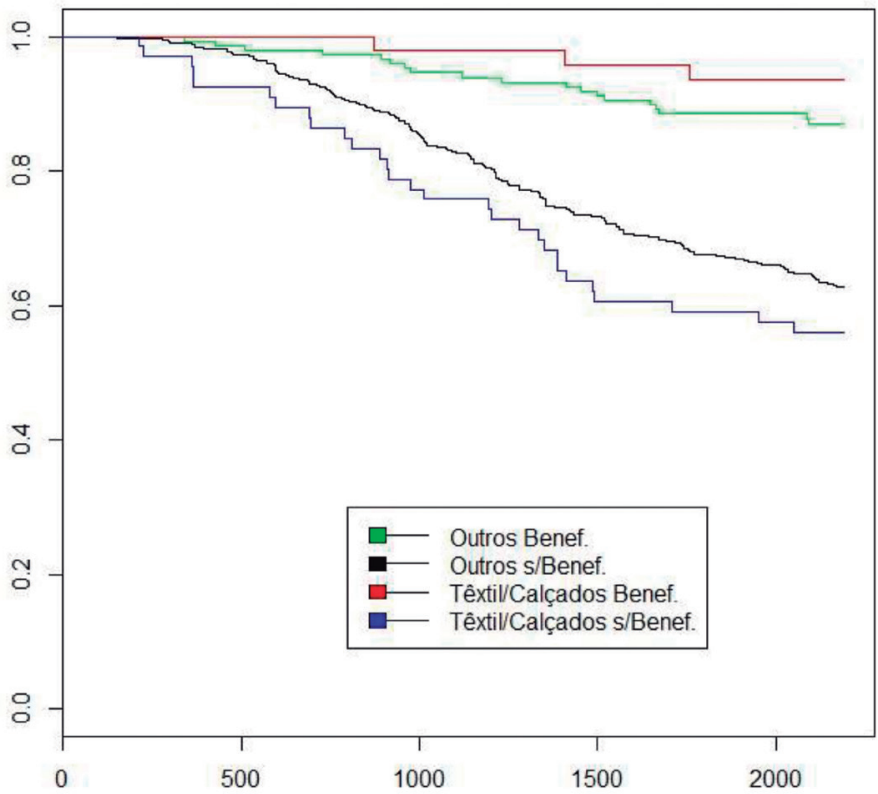

Elaboração e estimativas do autor.

Obs.: Figura reproduzida em baixa resolução e cujos leiaute e textos não puderam ser padronizados e revisados em virtude das condições técnicas dos originais (nota do Editorial).

TABELA 5

Sumário das curvas de sobrevivência estimadas: cenário 3

\begin{tabular}{|c|c|c|c|c|c|}
\hline \multirow{3}{*}{$\begin{array}{l}\text { Tempo } \\
\text { (dias) }\end{array}$} & \multicolumn{4}{|c|}{ Sobrevivência } & \multirow{3}{*}{$\begin{array}{c}\text { Diferença (a) versus } \\
\text { (d) }(\%)\end{array}$} \\
\hline & \multicolumn{2}{|c|}{ Têxtil/calçados } & \multicolumn{2}{|c|}{ Outros } & \\
\hline & Beneficiários (a) & Não beneficiários (b) & Beneficiários (c) & Não beneficiários (d) & \\
\hline 0 & 1,0000 & 1,0000 & 1,0000 & 1,0000 & 0,00 \\
\hline 365 & 1,0000 & 0,9240 & 0,9930 & 0,9870 & 1,32 \\
\hline 730 & 1,0000 & 0,8640 & 0,9730 & 0,9250 & 8,11 \\
\hline 1.095 & 0,9790 & 0,7580 & 0,9460 & 0,8280 & 18,24 \\
\hline 1.460 & 0,9570 & 0,6360 & 0,9180 & 0,7340 & 30,38 \\
\hline 1.825 & 0,9360 & 0,5910 & 0,8840 & 0,6760 & 38,46 \\
\hline 2.190 & 0,9360 & 0,5610 & 0,8710 & 0,6270 & 49,28 \\
\hline
\end{tabular}

Teste Peto-Peto: Est. $\chi 2=47,3(3 \mathrm{gl})$; Valor $p=3.02 \mathrm{e}-10$ 


\subsection{Cenário 4: empresas beneficiadas e não beneficiadas por receita total no período $2005-2010$}

No cenário 5, estudou-se a sobrevivência em função das receitas totais das empresas, dividindo-as por quartil e segmentando-as por beneficiadas e não beneficiadas. Constatou-se, como de era de se esperar, uma sobrevivência mais baixa para as empresas não beneficiadas e localizadas no $1^{\circ}$ quartil (receitas mais baixas no período). Deve-se, entretanto, alertar que como empresas baixadas têm receitas nulas, isso pode ter influenciado o resultado da análise. Novamente, constatou-se a vantagem das empresas beneficiadas sobre as náo beneficiadas. O gráfico 6 apresenta as curvas de sobrevivência em função da receita total.

GRÁFICO 6

Sobrevivência de empresas beneficiadas e não beneficiadas por receita total

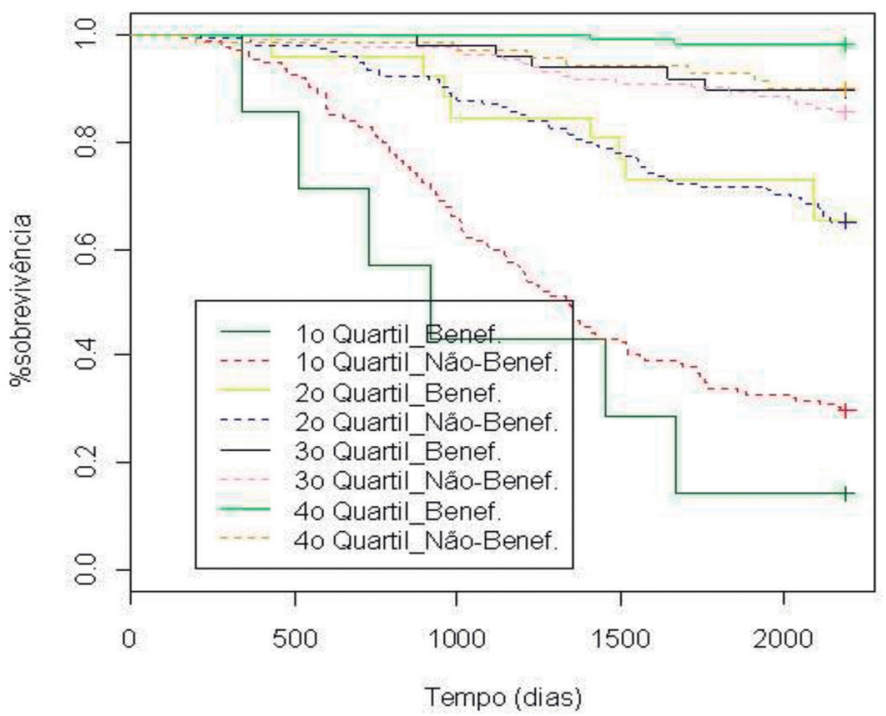

Elaboração e estimativas do autor.

Obs.: Figura reproduzida em baixa resolução e cujos leiaute e textos não puderam ser padronizados e revisados em virtude das condições técnicas dos originais (nota do Editorial).

As empresas (beneficiadas e não beneficiadas) foram divididas em quatro grupos, em funçáo de suas receitas totais ao longo dos seis anos em análise (2005-2010):

- $\quad$ 1 quartil: receitas no período até $\mathrm{R} \$ 2.232 .000,00$;

- $\quad 2^{\circ}$ quartil: receitas entre $\mathrm{R} \$ 2.232 .000,00$ e $\mathrm{R} \$ 15.210 .000,00$ (exclusive);

- 3o quartil: receitas entre $\mathrm{R} \$ 15.210 .000,00$ e $\mathrm{R} \$ 66.690 .000,00$ (exclusive); e

- $\quad 4^{\circ}$ quartil: receitas maiores que $\mathrm{R} \$ 66.690 .000,00$. 
TABELA 6

Sumário das curvas de sobrevivência estimadas: cenário 4

\begin{tabular}{|c|c|c|c|c|c|c|c|c|c|}
\hline \multirow{3}{*}{$\begin{array}{l}\text { Tempo } \\
\text { (dias) }\end{array}$} & \multicolumn{8}{|c|}{ Sobrevivência } & \multirow{3}{*}{$\begin{array}{l}\text { Diferença } \\
\text { (g) versus } \\
\text { (b) }(\%)\end{array}$} \\
\hline & \multicolumn{2}{|c|}{$1^{\circ}$ quartil } & \multicolumn{2}{|c|}{$2^{\circ}$ quartil } & \multicolumn{2}{|c|}{ 3o quartil } & \multicolumn{2}{|c|}{$4^{\circ}$ quartil } & \\
\hline & $\begin{array}{c}\text { Beneficiários } \\
\text { (a) }\end{array}$ & $\begin{array}{l}\text { Não } \\
\text { beneficiários } \\
\text { (b) }\end{array}$ & $\begin{array}{c}\text { Beneficiários } \\
\text { (c) }\end{array}$ & $\begin{array}{l}\text { Não } \\
\text { beneficiários } \\
\text { (d) }\end{array}$ & $\begin{array}{c}\text { Beneficiários } \\
\text { (e) }\end{array}$ & $\begin{array}{c}\text { Não } \\
\text { beneficiários } \\
\text { (f) }\end{array}$ & $\begin{array}{c}\text { Beneficiários } \\
\text { (g) }\end{array}$ & $\begin{array}{l}\text { Não } \\
\text { beneficiários } \\
\text { (h) }\end{array}$ & \\
\hline 0 & 1,0000 & 1,0000 & 1,0000 & 1,0000 & 1,0000 & 1,0000 & 1,0000 & 1,0000 & 0,0 \\
\hline 365 & 0,8570 & 0,9600 & 1,0000 & 0,9870 & 1,0000 & 0,9920 & 1,0000 & 0,9860 & 4,2 \\
\hline 730 & 0,5710 & 0,8290 & 0,9620 & 0,9350 & 1,0000 & 0,9770 & 1,0000 & 0,9860 & 20,6 \\
\hline 1.095 & 0,4290 & 0,6060 & 0,8460 & 0,8710 & 0,9800 & 0,9620 & 1,0000 & 0,9710 & 65,0 \\
\hline 1.460 & 0,2860 & 0,4290 & 0,8080 & 0,7870 & 0,9390 & 0,9170 & 0,9910 & 0,9430 & 131,0 \\
\hline 1.825 & 0,1430 & 0,3370 & 0,7310 & 0,7160 & 0,8980 & 0,9020 & 0,9820 & 0,9290 & 191,4 \\
\hline 2.190 & 0,1430 & 0,2970 & 0,6540 & 0,6520 & 0,8980 & 0,8560 & 0,9820 & 0,9000 & 230,6 \\
\hline
\end{tabular}

Elaboração e estimativas do autor.

\subsection{Cenário 5: empresas beneficiadas por percentual do benefício sobre a receita total}

No cenário 6, estudou-se a sobrevivência das empresas beneficiadas em função do percentual auferido de benefício sobre as receitas totais. As empresas foram divididas em quatro grupos:

- $\quad 1^{\circ}$ quartil: benefício inferior a $1,545 \%$ das receitas totais;

- $\quad 2$ - quartil: benefício entre $1,545 \%$ e $2,90 \%$ (exclusive);

- $\quad 3$ o quartil: benefício entre $2,90 \%$ e $5,13 \%$ (exclusive); e

- $\quad 4^{\circ}$ quartil: benefício superior a $5,13 \%$.

Conforme se pode observar no gráfico 7 e na tabela 6 , as empresas cujo benefício superam $3,41 \%$ da receita total ( $4^{\circ}$ quartil) têm o maior nível de sobrevivência (92\%) ao final do sexto ano de observação. Ressalte-se, entretanto, que as curvas de sobrevivência das empresas dos três outros quartis sáo muito semelhantes, especialmente ao final do período de seis anos, variando entre $87,2 \%$ e $87,8 \%$, o que parece indicar que o percentual do benefício não é determinante para a sobrevivência das empresas. 
GRÁFICO 7

Sobrevivência das empresas beneficiadas em função do percentual do benefício sobre a receita total

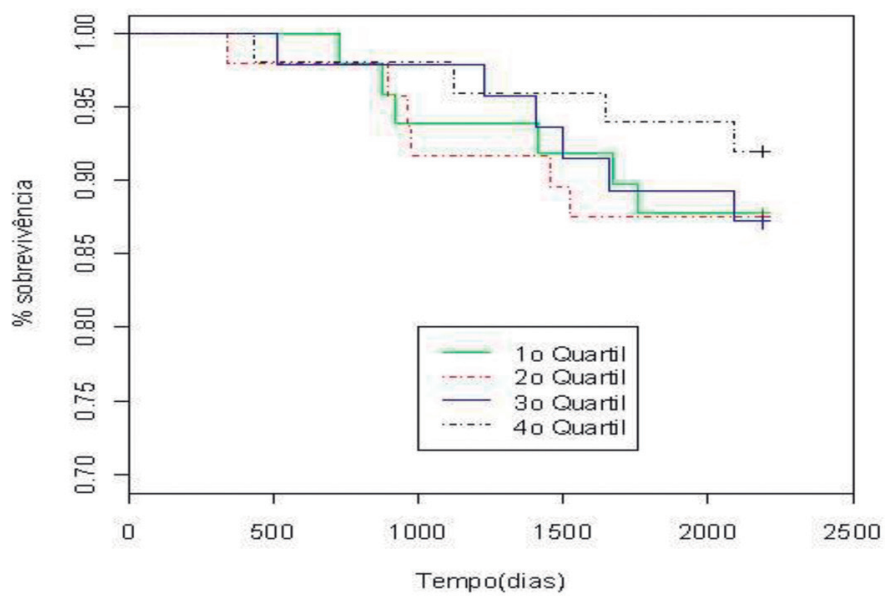

Elaboração e estimativas do autor.

Obs.: Figura reproduzida em baixa resolução e cujos leiaute e textos não puderam ser padronizados e revisados em virtude das condições técnicas dos originais (nota do Editorial).

TABELA 7

Sumário das curvas de sobrevivência estimadas: cenário 5

\begin{tabular}{|c|c|c|c|c|c|}
\hline \multirow{2}{*}{ Tempo (dias) } & \multicolumn{4}{|c|}{ Sobrevivência } & \multirow{2}{*}{$\begin{array}{r}\text { Diferença }(\mathrm{g}) \\
\text { versus (b) }(\%)\end{array}$} \\
\hline & $1{ }^{\circ}$ quartil & $2^{\circ}$ quartil & $3 \circ$ quartil & $4 \circ$ quartil & \\
\hline 0 & 1,0000 & 1,0000 & 1,0000 & 1,0000 & 0,00 \\
\hline 365 & 1,0000 & 0,9790 & 1,0000 & 1,0000 & 0,00 \\
\hline 730 & - & 0,9790 & 0,9790 & 0,9800 & - \\
\hline 1.095 & 0,9390 & 0,9170 & 0,9790 & 0,9800 & 4,37 \\
\hline 1.460 & 0,9180 & 0,8960 & 0,9380 & 0,9590 & 4,47 \\
\hline 1.825 & 0,8780 & 0,8750 & 0,8960 & 0,9390 & 6,95 \\
\hline 2.190 & 0,8780 & 0,8750 & 0,8750 & 0,9180 & 4,56 \\
\hline
\end{tabular}

Teste Peto-Peto: Est. $\chi 2=0.7(3 \mathrm{gl})$; Valor $p=0,874$

Elaboração e estimativas do autor.

\section{MODELO DE RISCOS PROPORCIONAIS DE COX}

Nesta seção, o modelo proposto por Cox (1972) é brevemente apresentado. ${ }^{10}$ $\mathrm{O}$ modelo de riscos proporcionais de Cox (daqui por diante simplesmente modelo de Cox) é um modelo de regressão semiparamétrico, o qual estima a taxa 
instantânea de falha, possibilitando a inclusão de covariáveis. Em sua formulação mais utilizada (e adotada neste trabalho), o modelo de Cox é especificado como:

$$
\lambda(t)=\lambda_{0}(t) \exp \left(\beta^{\prime} z\right),
$$

em que, $\lambda(t)$ é a taxa instantânea de falha na vizinhança a direita ${ }^{11}$ de $t, \lambda_{0}(t)$ é chamada função-base (a taxa de falha na ausência de covariáveis), $z$ é o vetor de covariáveis do modelo e $\beta$ é o vetor de parâmetros a serem estimados.

O modelo de Cox é estimado por meio do método da máxima verossimilhança com a modificação proposta por Breslow (1972) e Peto (1972) de modo a incorporar observações empatadas (observaçóes que falham no mesmo tempo).

\subsection{Resultados do modelo de Cox}

O modelo econométrico especificado nesta seção utiliza como covariáveis as mesmas variáveis utilizadas na estimação das curvas de sobrevivência. Especificamente, as covariáveis seguem a seguinte descrição:

- fdi: é uma variável binária em que 1 indica que a empresa é beneficiada;

- local: é uma variável binária em que 1 indica que a empresa está localizada na RM de Fortaleza;

- setor: é uma variável binária em que 1 indica que a empresa pertence ao setor têxtil ou de calçados;

- vlr_ben: é a proporção do benefício recebido pela empresa em relação à sua receita;

- $\quad j Q$ : indica o j-ésimo quartil de receita; os quartis de receita são variáveis categóricas em que o primeiro quartil é a categoria-base; e

- jQ x fdi: é a combinação do j-ésimo quartil de receita com a variável que indica se a empresa recebeu ou não o benefício.

Note que, diferente do que foi feito nas estimativas das curvas de sobrevivência, na especificação do modelo de Cox os quartis de receita aparecem isoladamente e também interagindo com a variável que se expressa ou não a empresa recebeu algum benefício do FDI. Na tabela 8, é mostrado o exponencial do coeficiente estimado, a fim de se obter interpretaçóes mais diretas.

$\overline{\text { 11. Formalmente: } \lambda(t)}=\lim _{h \downarrow 0} \frac{\operatorname{Pr}[t \leq T \leq t+h \mid T \geq t]}{h}$ 
TABELA 8

Resultados do modelo de Cox

\begin{tabular}{|c|c|c|c|c|}
\hline Variável & Exponencial (coeficiente) & Desvio-padrão & Estatística z & Valor $p$ \\
\hline fdi & 3,1432 & 0,4355 & 2,63 & 0,00855 ** \\
\hline local & 2,5514 & 0,1972 & 4,75 & $204 \mathrm{e}-06^{* * *}$ \\
\hline setor & 2,3233 & 0,2016 & 4,18 & $2,89 \mathrm{e}-05^{* * *}$ \\
\hline vlr_ben & 1,0000 & 0,0000 & $-0,76$ & 0,44955 \\
\hline $2 Q$ & 0,3418 & 0,1650 & $-6,51$ & $7,66 \mathrm{e}-11$ *** \\
\hline $3 Q$ & 0,1184 & 0,2483 & $-8,59$ & $<2 \mathrm{e}-16^{* * *}$ \\
\hline $4 Q$ & 0,0734 & 0,3919 & $-6,67$ & $2,64 \mathrm{e}-11$ *** \\
\hline $2 Q \times$ fdi & 0,3167 & 0,5667 & $-2,03$ & 0,04246 * \\
\hline $3 Q \times$ fdi & 0,2352 & 0,6863 & $-2,11$ & 0,03494 * \\
\hline $4 Q \times$ fdi & 0,1163 & 1,0430 & $-2,06$ & 0,03916 * \\
\hline
\end{tabular}

Elaboração e estimativas do autor.

Obs.: * Nível de significância: $p<0,05 .{ }^{* *}$ Nível de significância: $p<0,01 .{ }^{* * *}$ Nível de significância: $p<0,001$.

Por inspeção da tabela 8, conclui-se que o modelo apresenta significância global e, exceto pela variável que expressa o valor do benefício concedido, as demais apresentaram significância isoladamente. Note que quando o exponencial do coeficiente é maior do que 1 , entâo a covariável associada acelera a taxa de falha; do contrário, a covariável associada ao coeficiente com exponencial menor do que um desacelera a taxa de falha. Nota-se, portanto, que, no caso do FDI, se uma empresa ingressa no programa, então a taxa de falha acelera. A princípio, isso contradiz os resultados mostrados no cenário 1, em que a curva de sobrevivência estimada para as empresas beneficiadas é quase uniformemente superior à curva de sobrevivência estimada para as empresas que não receberam o benefício. O mesmo pode ser dito a respeito das empresas situadas na RM de Fortaleza, bem como sobre aquelas pertencentes aos setores têxtil ou de calçados.

Quando são considerados os quartis de receita ocorre o inverso. De fato, empresas que saltam do primeiro para qualquer quartil de receita acima desaceleram a taxa de falha, mais do que isso, a desaceleração é maior conforme é maior o quartil. Outro ponto de interesse é que, considerando o terceiro quartil, o efeito de desaceleração na taxa de falha é maior quando se considera a iteração com o benefício do FDI. Portanto, muito embora os resultados sugiram que a taxa de falha acelera com o recebimento do benefício, em combinação com as classes de receita pode-se inferir alguma eficácia do programa, ao menos quanto à sobrevivência das empresas. 
Para ilustrar esse último ponto, considere as empresas no terceiro quartil de receita. Neste caso, ceteris paribus, a razão entre as taxas de falha estimadas mostra que a taxa de falha para empresas que recebem o benefício do programa é $62 \%$ da taxa de falha daquelas que não recebem esse benefício.

\section{CONCLUSÃO}

O objetivo do presente estudo é compreender um pouco mais a dinâmica da sobrevivência das empresas beneficiadas pelo FDI/Provin, respondendo, assim, às questôes levantadas na introdução.

Com o propósito de dar robustez aos resultados obtidos, diferentes cenários foram propostos para análise. No cenário 1, tem-se a comparaçáo da sobrevivência das empresas beneficiadas ante as não beneficiadas, sem qualquer outra delimitação. Respondendo à primeira questão levantada na introdução, pode-se observar que a sobrevivência das empresas beneficiadas é superior à sobrevivência das empresas não beneficiadas. Já ao final dos primeiros 365 dias, tem-se uma diferença de 1,6 pontos percentuais (p.p.) entre a sobrevivência dos dois grupos, diferença que sobe para 26,9 p.p. ao final do sexto ano de observação.

O cenário 2 considera a localização das empresas, comparando aquelas que estão ou náo localizadas na RM de Fortaleza (quinze municípios). A menor sobrevivência foi encontrada no grupo de empresas náo beneficiadas e localizadas na RM de Fortaleza (56,9\% ao final do sexto ano), resultado compatível com o encontrado no cenário 1 . No que concerne ao melhor desempenho, entretanto, o melhor resultado foi obtido pelas empresas beneficiadas e localizadas no interior do estado (93,1\%). O resultado encontrado no cenário 3 reforça a questão do elevado nível de concorrência encontrado no cenário 2 , mas levanta a dúvida quanto ao peso da atividade econômica desenvolvida para a sobrevivência da empresa, tendo em vista a concentração de empresas do segmento de confecção localizadas na RM de Fortaleza.

O cenário 4 investiga a sobrevivência em função da atividade econômica. Para tanto, os setores mais representativos da amostra quanto à receita, notadamente, têxtil e calçado, foram comparados aos demais. Os resultados mostram que, entre as empresas beneficiadas, aquelas pertencentes aos setores têxtil ou de calçados possuem sobrevivência maior, ocorrendo o contrário quando consideradas as empresas não beneficiadas. Comparando-se empresas beneficiadas e pertencentes ao setor têxtil ou de calçados com as empresas não beneficiadas e pertencentes aos outros setores, estimou-se uma diferença na probabilidade de sobrevivência no último período de $49,28 \%$. 
A resposta ao questionamento sobre o impacto do nível de faturamento na sobrevivência (cenário 4) foi a que pareceu menos conclusiva. Como pode ser observado no gráfico 6 , os grupos de empresas com menor faturamento foram os que apresentaram menor sobrevivência. Entretanto, a análise pode ter sido influenciada pelo fato de que empresas baixadas têm faturamento nulo.

No cenário 5, as empresas beneficiadas foram segmentadas em quatro grupos, de acordo com o percentual do benefício em relação à receita. Conforme pode ser observado no gráfico 7 e na tabela 7 , os resultados náo mostraram diferenças significativas entres os quartis. Apesar disso, considerando o último período, a diferença na probabilidade de sobrevivência entre as empresas situadas no $2^{\circ}$ e $4^{\circ}$ quartil foi de 4,56\% em favor do último grupo.

Em adição às análises das curvas de sobrevivência, um modelo de regressão de Cox foi proposto, utilizando como covariáveis àquelas aplicadas para segmentar as estimativas de Kaplan-Meier. Os resultados mostram que receber o benefício do FDI é efetivo entre firmas de porte maior (segundo a receita). Esse resultado sugere que se o objetivo for aumentar a sobrevivência das empresas o programa deve visar empresas de médio a grande porte. Com relação à localização e ao setor, os resultados concordam com a análise não paramétrica. Por fim, tal qual ocorreu com as curvas de sobrevivência estimadas, o quartil do benefício em relação à receita não foi significante.

Diante do que foi exposto, pode-se concluir que empresas beneficiadas têm efetivamente níveis de sobrevivência superiores aos das empresas não beneficiadas, o que náo significa, entretanto, que basta ser beneficiada para ter elevados níveis de sobrevivência. Empresas localizadas em Fortaleza, mesmo as beneficiadas, possuem níveis mais baixos de sobrevivência, provavelmente em face do ambiente mais competitivo. Os níveis mais baixos de sobrevivência das empresas dos setores têxtil e de confecção também sugerem que conceder o benefício fiscal não parece ser suficiente. Talvez sejam necessárias políticas públicas de apoio à inovação, ao desenvolvimento tecnológico, à inclusão em cadeias produtivas, entre outros, como sugerido por Amaral Filho (2001).

\section{REFERÊNCIAS}

ALMAWI, A. M. 2009. Dissertação (Mestrado) - Faculdade de Economia e Finanças, Ibmec, Rio de Janeiro, 2009.

AMARAL FILHO, J. A endogeneização no desenvolvimento econômico regional e local. Planejamento e Políticas Públicas, v. 23, p. 261-286, 2001. 
AMARAL FILHO, J. É negócio ser pequeno, mas em grupo. In: SEMINÁRIO DESENVOLVIMENTO EM DEBATE, PAINÉIS DO DESENVOLVIMENTO, 2., 2002, Rio de Janeiro. Anais... Rio de Janeiro: BNDES, 2002.

BRESLOW, N. E. Contribution to the discussion on the paper by D. R. Cox, Regression modelos and laife-tables. Journal of the Royal Statistical Society, (B), v. 34, p. 216-217, 1972.

CARVALHO, J. R.; BARRETO, F. A.; OLIVEIRA, V. H. Avaliaçáo econométrica do Fundo de Desenvolvimento Industrial do Ceará (FDI). Fortaleza: Ipece, 2007.

CEARÁ. Lei no 13.377 , de 29 de setembro de 2003. Altera os arts. 2o e 5 da Lei no 10.367 , de 7 de dezembro de 1979, que instituiu o Fundo de Desenvolvimento Industrial (FDI) do Estado do Ceará, na forma que indica, e dá outras providências. Diário Oficial do Estado do Ceará, 29 set. 2003.

CEARÁ. Anuário Estatístico do Ceará 2016. Ceará: Instituto de Pesquisa e Estratégia Econômica do Ceará (Ipece), 2016.

COLOSIMO, E. A; GIOLO, S. R. Análise de sobrevivência aplicada. 1. Ed. São Paulo: Edgar Bucler, 2006.

COX, D. R. Regression models and life-tables. Journal of the Royal Statistical Society, v. 34, n. 2, p. 187-220, 1972. (Series B Methodological).

IRRFI, G; NOGUEIRA, F. A. N, BARRETO, F. A. Efeitos da política de atraçáo de incentivos industriais no Ceará sobre o emprego no período 2002-2005. Fortaleza: UFC, 2009. Disponível em: <https://bit.ly/3kjjwp2>.

MOURAO, P. Dissecting the Survivors: how the age of a club contributes to the ability of a team to maintain the top position in the European soccer leagues. Science and Sports, v. 32, n. 4, p. 163-171, 2017.

NUNES, A.; SARMENTO, E. A sobrevivência de empresas na região Norte. Boletim Mensal da Economia Portuguesa, n. 28 p. 49-58, 2010.

PETO, R. Contribution to the discussion on the paper by D. R. Cox, Regression Modelos and Laife-Tables. Journal of the Royal Statistical Society, (B), v. 34, p. 205-207, 1972.

PONTES, P. A.; VIANNA, P. J. R. Análise da política de incentivo ao desenvolvimento industrial do estado do Ceará no período 2001-2004. Fortaleza: Ipece. 2005.

SEBRAE - SERVIÇO BRASILEIRO DE APOIO ÀS MICRO E PEQUENAS EMPRESAS. Taxa de sobrevivência das empresas no Brasil. Brasília: Sebrae, 2011. Disponível em: <https://bit.ly/3dKFmQ8>. 
SOUSA, P. F. Impactos da política estadual de incentivos fiscais sobre a arrecadação de ICMS no estado do Ceará. 2008. Dissertação (Mestrado) - Universidade Federal do Ceará, Fortaleza, 2008.

VARSANO, R. A guerra fiscal do ICMS: quem ganha e quem perde. Planejamento e Políticas Públicas, v. 15, p. 3-19, 1997.

\section{BIBLIOGRAFIA COMPLEMENTAR}

ALLISON, P. D. Survival Analysis Using SAS: a practical guide. 2. Ed. Cary, NC: SAS Institute Inc, 2010.

AMARAL FILHO, J. et al. Núcleos e arranjos produtivos locais: casos do Ceará. Fortaleza: Ipece, 2011.

CEARÁ. Decreto no 27.070, de 28 de maio de 2003. Regulamenta a Lei no 13.298, de 2 de abril de 2003, que estabelece tratamento diferenciado, simplificado e favorecido às microempresas e empresas de pequeno porte, e dá outras providências. Diário Oficial do Estado, Poder Executivo, Fortaleza, 30 maio 2003.

. Instrução Normativa no 40, de 30 de dezembro de 2004. Dispóe sobre a fixação de valores relativos à cobrança da taxa de fiscalização e prestação de serviço público para o exercício de 2005. Diário Oficial do Estado, Poder Executivo, Fortaleza, 29 dez. 2004.

FONTENELLE, O. F. Uma investigaçáo dos fatores econômicos que influenciam na sobrevida de micro e pequenas empresas do estado do Ceará no período 2002-2006. 2009. Dissertação (Mestrado) - Curso de Pós-graduação em Economia, Universidade Federal do Ceará, Fortaleza, 2009.

MIGNOZZETTI, U. G. Introdução ao $\boldsymbol{R}$ Commander. São Paulo: Caeni/USP, 2009. Disponível em: <https://bit.ly/2TaT1pV>.

OLIVEIRA, A. L. Incentivos fiscais: o impacto na geração de empregos no estado do Ceará. 2010. Dissertação (Mestrado) - Curso de Pós-graduação em Economia, Universidade Federal do Ceará, Fortaleza, 2010.

SARKAR, D. Statistics With R: Survival Analysis. Madison: University of Wisconsin, 2005. Disponível em: <https://bit.ly/3m68Niw>.

SILVA, N. L. C. Uma resenha sobre a competição tributária entre jurisdiçóes. Rio de Janeiro: Ipea, 2001. (Texto para Discussão, n. 819).

WILDASIN, D. Nash Equilibria in Models of Fiscal Competition. Journal of Public Economics, v. 35, n. 2, p. 229-240, 1988.

ZHOU, M. Use Software R to do Survival Analysis and Simulation. A tutorial. Lexington: Department of Statistics; University of Kentuck, [s.d.]. Disponível em: $<$ https://bit.ly/3dJIUCb $>$. 


\section{APÊNDICE A}

Neste apêndice são apresentados os resultados das estimativas das curvas de sobrevivência entre diferentes setores da indústria. As empresas foram divididas em onze grandes grupos de atividades econômicas, conforme relação a seguir.

1) Indústria de produtos alimentícios, refrigerantes e cervejas.

2) Indústria têxtil e confecçôes.

3) Indústria de curtimento e fabricação de calçados.

4) Indústria de papel e embalagem.

5) Fabricação de produtos químicos e medicamentos.

6) Fabricação de artefatos de borracha e plástico.

7) Fabricação de produtos metálicos, não metálicos e metalurgia.

8) Fabricação de máquinas, aparelhos e materiais elétricos.

9) Fabricação de veículos, automóveis e carrocerias.

10) Fabricação de móveis e colchōes.

11) Outros.

Conforme pode ser observado nas tabelas de $\mathrm{A} 1 \mathrm{a} \mathrm{A} 4$, as empresas não beneficiadas, especialmente as localizadas na Região Metropolitana (RM) de Fortaleza, apresentam as mais baixas taxas de sobrevivência. Enquanto para o grupo de empresas beneficiadas, a sobrevivência em quase todos os grupos de atividade supera os $80 \%$ ao final do sexto ano de pesquisa, os grupos de empresas não incentivadas têm a quase totalidade dos grupos estudados com índice inferior a $75 \%$, ressaltando-se que, novamente, as empresas não beneficiadas da RM de Fortaleza apresentam os piores índices, provavelmente em função do nível mais alto de competitividade.

TABELA A. 1

Sumário do cenário 4: empresas não beneficiárias - RM de Fortaleza

\begin{tabular}{lccc}
\hline Atividade & Total & Baixas & Sobrevivência (\%) \\
\hline Indústria de papel e embalagem & 6 & 4 & 33,3 \\
Indústria de curtimento e calçados & 14 & 8 & 42,9 \\
Indústria têxtil e confecção & 186 & 99 & 46,8 \\
Fabricação de móveis e colchões & 12 & 6 & 50,0 \\
Fabricação de produtos metálicos, não metálicos e metalurgia & 38 & 18 & 52,6 \\
Fabricação de artefatos de borracha e plástico & 16 & 6 & 62,5 \\
Fabricação de máquinas, aparelhos e material elétrico & 14 & 5 & 64,3 \\
Outras & 14 & 4 & 71,4 \\
Fabricação de produtos químicos e medicamentos & 27 & 7 & 74,1 \\
Produtos alimentícios, refrigerantes e cerveja & 66 & 14 & 78,8 \\
Fabricação de veículos, automóveis e carrocerias & 4 & 0 & 100,0 \\
\hline
\end{tabular}


TABELA A.2

Sumário do cenário 4: empresas não beneficiárias - interior

\begin{tabular}{lccc}
\hline Atividade & Total & Baixas & Sobrevivência (\%) \\
\hline Fabricação de artefatos de borracha e plástico & 3 & 2 & 33,3 \\
Fabricação de móveis e colchões & 6 & 3 & 50,0 \\
Indústria têxtil e confecção & 23 & 10 & 56,5 \\
Indústria de curtimento e calçados & 27 & 11 & 59,3 \\
Fabricação de produtos metálicos, não metálicos e metalurgia & 10 & 2 & 80,0 \\
Produtos alimentícios, refrigerantes e cerveja & $\mathbf{5 2}$ & 4 & 92,3 \\
Fabricação de máquinas, aparelhos e material elétrico & $\mathbf{1}$ & 0 & 100,0 \\
Fabricação de produtos químicos e medicamentos & $\mathbf{3}$ & 0 & 100,0 \\
Indústria de papel e embalagem & $\mathbf{2}$ & 0 & 100,0 \\
Outras & $\mathbf{8 0}$ & & 100,0 \\
\hline
\end{tabular}

TABELA A. 3

Sumário do cenário 4: empresas beneficiadas - RM de Fortaleza

\begin{tabular}{lccc}
\hline Atividade & Total & Baixas & Sobrevivência (\%) \\
\hline Fabricação de móveis e colchões & 2 & 1 & 50,0 \\
Indústria de curtimento e calçados & 4 & 1 & 75,0 \\
Indústria têxtil e confecção & 35 & 6 & 82,9 \\
Indústria de papel e embalagem & 13 & 2 & 84,6 \\
Fabricação de produtos metálicos, não metálicos e metalurgia & 21 & 3 & 85,7 \\
Fabricação de produtos químicos e medicamentos & 15 & 2 & 86,7 \\
Fabricação de máquinas, aparelhos e material elétrico & 8 & 1 & 87,5 \\
Fabricação de artefatos de borracha e plástico & 11 & 1 & 90,9 \\
Outras & 11 & 1 & 90,9 \\
Fabricação de veículos, automóveis e carrocerias & 4 & 0 & 100,0 \\
Produtos alimentícios, refrigerantes e cerveja & 12 & 0 & 100,0 \\
\hline
\end{tabular}

Elaboração do autor.

TABELA A.4

Sumário do cenário 4: empresas beneficiadas - interior

\begin{tabular}{lccc}
\hline Atividade & Total & Baixas & Sobrevivência (\%) \\
\hline Outras & 3 & 1 & 66,7 \\
Produtos alimentícios, refrigerantes e cerveja & 10 & 3 & 70,0 \\
Fabricação de artefatos de borracha e plástico & $\mathbf{5}$ & 0 & 100,0 \\
Fabricação de móveis e colchões & $\mathbf{5}$ & 0 & 100,0 \\
Fabricação de máquinas, aparelhos e material elétrico & $\mathbf{1}$ & $\mathbf{1 0 0 , 0}$ \\
Fabricação de produtos metálicos, não metálicos e metalurgia & 4 & 0 & 100,0 \\
Fabricação de produtos químicos e medicamentos & $\mathbf{1}$ & 0 & 100,0 \\
Fabricação de veículos, automóveis e carrocerias & $\mathbf{2}$ & 0 & 100,0 \\
Indústria de curtimento e calçados & $\mathbf{2 1}$ & 0 & 100,0 \\
Indústria têxtil e confecção & $\mathbf{6}$ & 0 & 100,0 \\
\hline
\end{tabular}

Elaboração do autor. 
GRÁFICO A.1

Alimentos

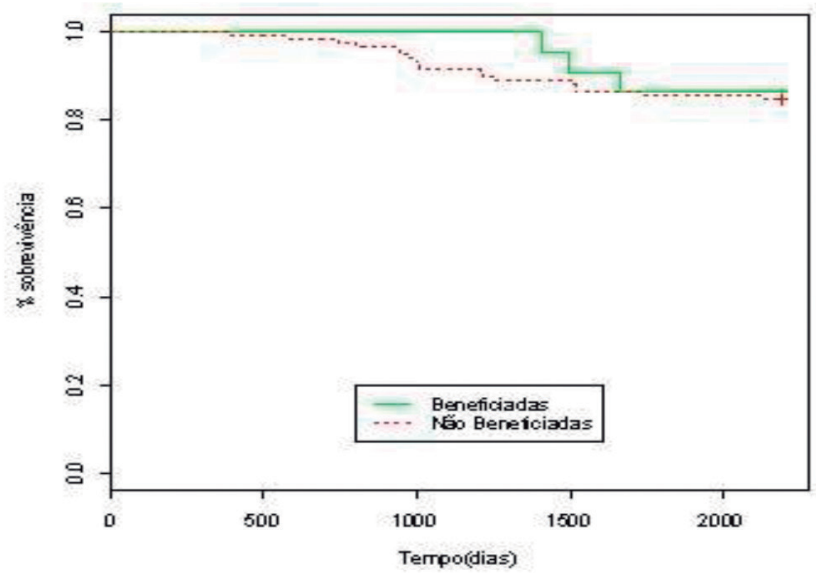

Elaboração do autor.

Obs.: Figura reproduzida em baixa resolução e cujos leiaute e textos não puderam ser padronizados e revisados em virtude das condições técnicas dos originais (nota do Editorial).

GRÁFICO A.2

Têxteis e confecções refrigerantes e cervejas

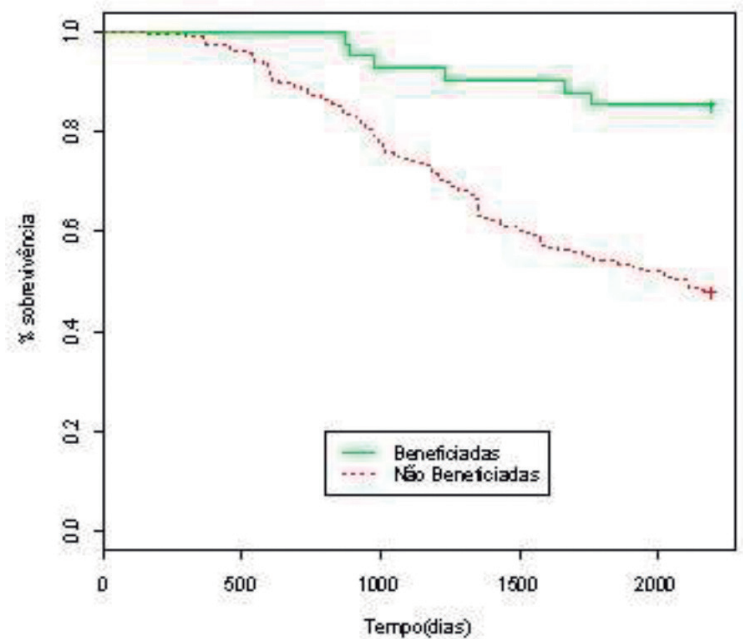

Elaboração do autor.

Obs.: Figura reproduzida em baixa resolução e cujos leiaute e textos não puderam ser padronizados e revisados em virtude das condições técnicas dos originais (nota do Editorial). 
GRÁFICO A.3

Curtimento e fabricação

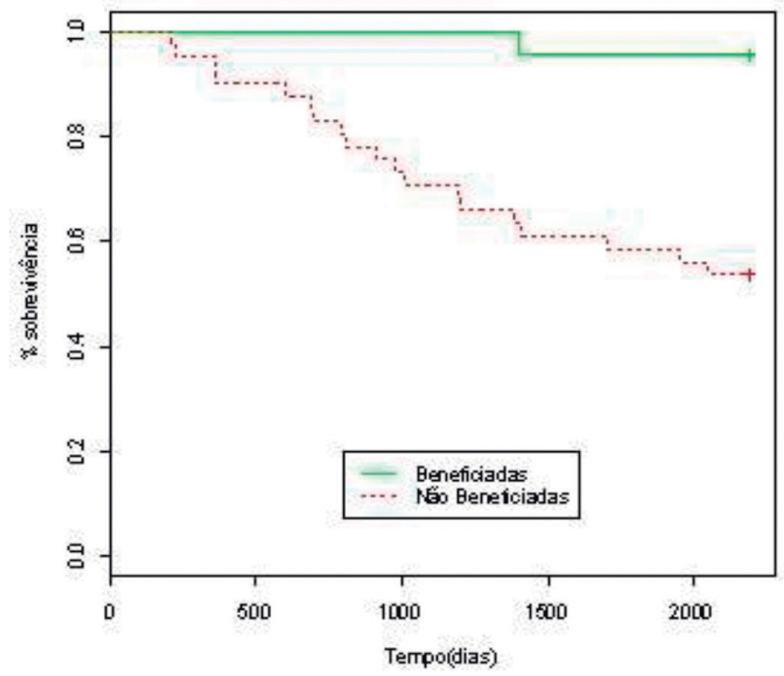

Elaboração do autor.

Obs.: Figura reproduzida em baixa resolução e cujos leiaute e textos não puderam ser padronizados e revisados em virtude das condições técnicas dos originais (nota do Editorial).

\section{GRÁFICO A.4}

\section{Papel e embalagem de calçados}

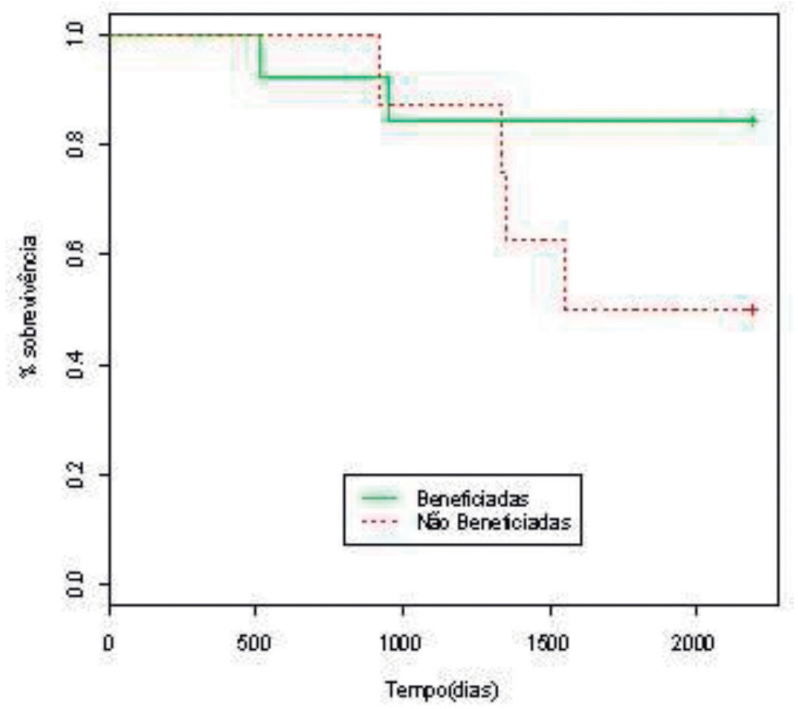

Elaboração do autor.

Obs.: Figura reproduzida em baixa resolução e cujos leiaute e textos não puderam ser padronizados e revisados em virtude das condições técnicas dos originais (nota do Editorial). 
GRÁFICO A.5

Produtos químicos e medicamentos

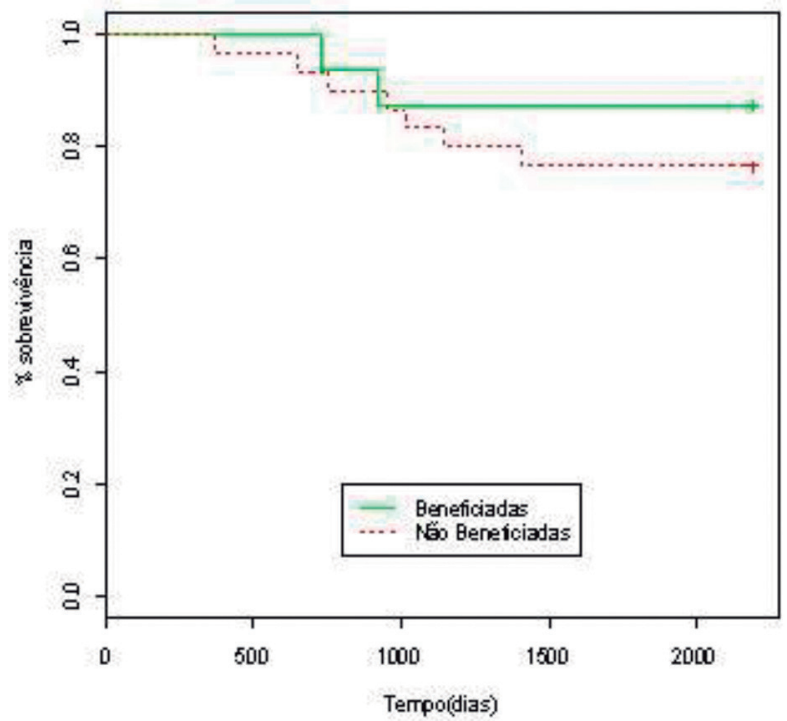

Elaboração do autor.

Obs.: Figura reproduzida em baixa resolução e cujos leiaute e textos não puderam ser padronizados e revisados em virtude das condições técnicas dos originais (nota do Editorial).

\section{GRÁFICO A.6}

\section{Artefatos de borracha e plásticos}

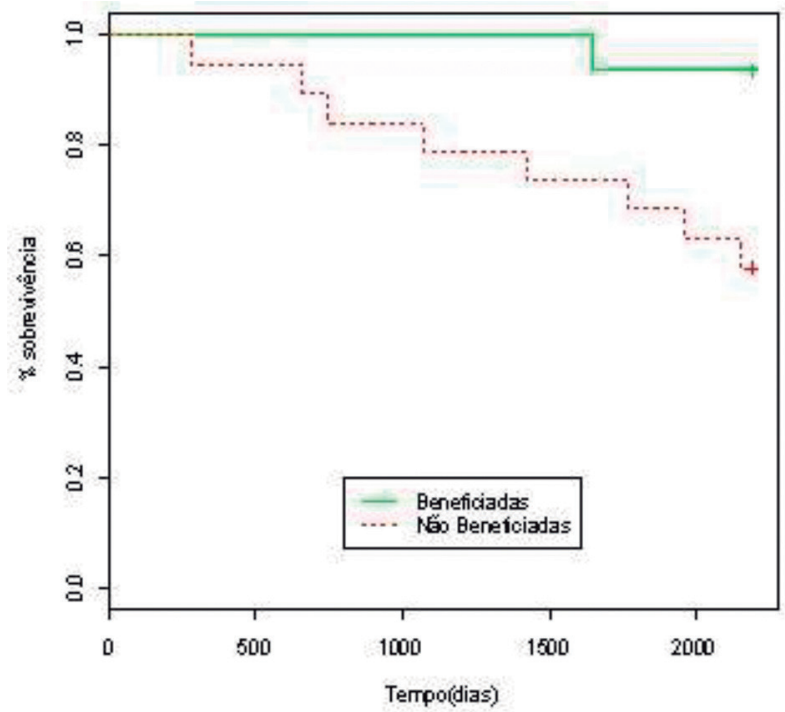

Elaboração do autor.

Obs.: Figura reproduzida em baixa resolução e cujos leiaute e textos não puderam ser padronizados e revisados em virtude das condições técnicas dos originais (nota do Editorial). 
GRÁFICO A.7

Produtos metálicos, não metálicos e metalurgia

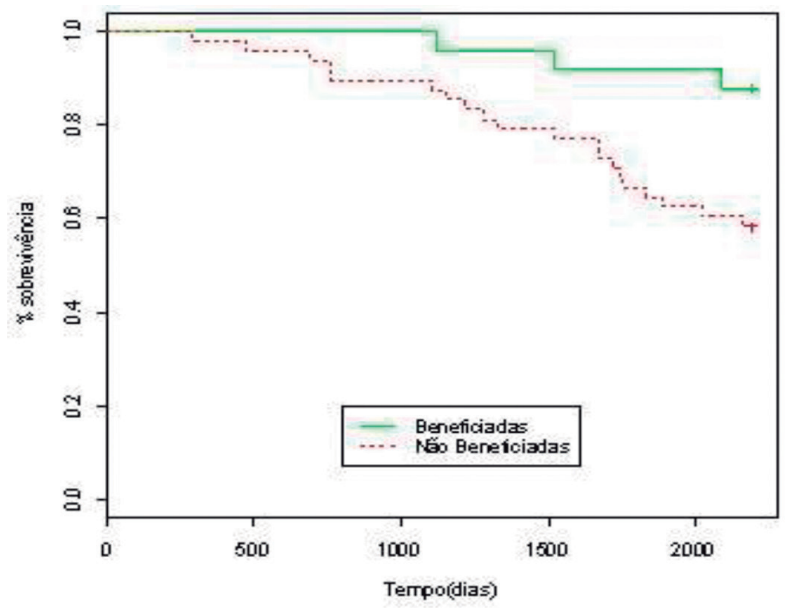

Elaboração do autor.

Obs.: Figura reproduzida em baixa resolução e cujos leiaute e textos não puderam ser padronizados e revisados em virtude das condições técnicas dos originais (nota do Editorial).

GRÁFICO A.8

Máquinas, aparelhos e materiais elétricos

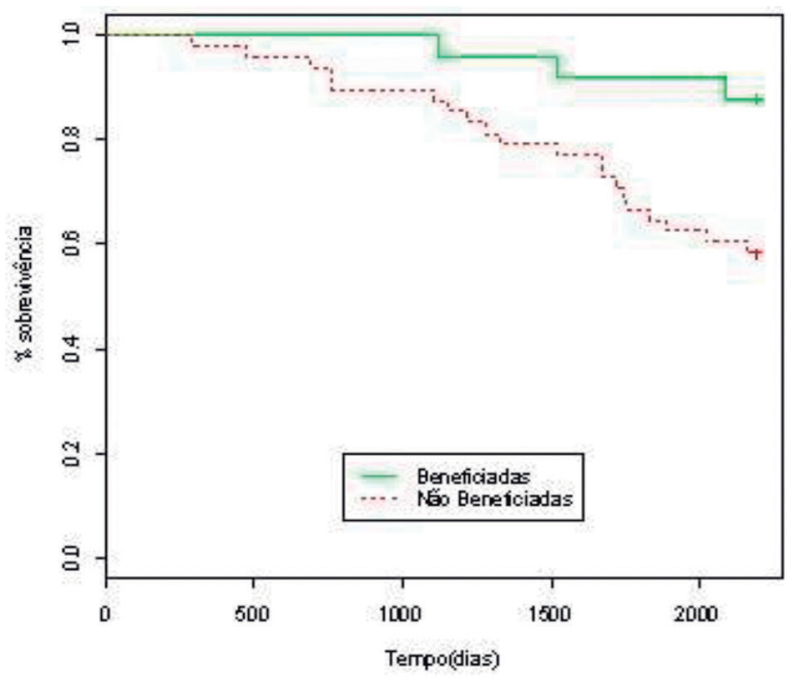

Elaboração do autor.

Obs.: Figura reproduzida em baixa resolução e cujos leiaute e textos não puderam ser padronizados e revisados em virtude das condições técnicas dos originais (nota do Editorial). 
GRÁFICO A.9

Veículos, automóveis e carrocerias

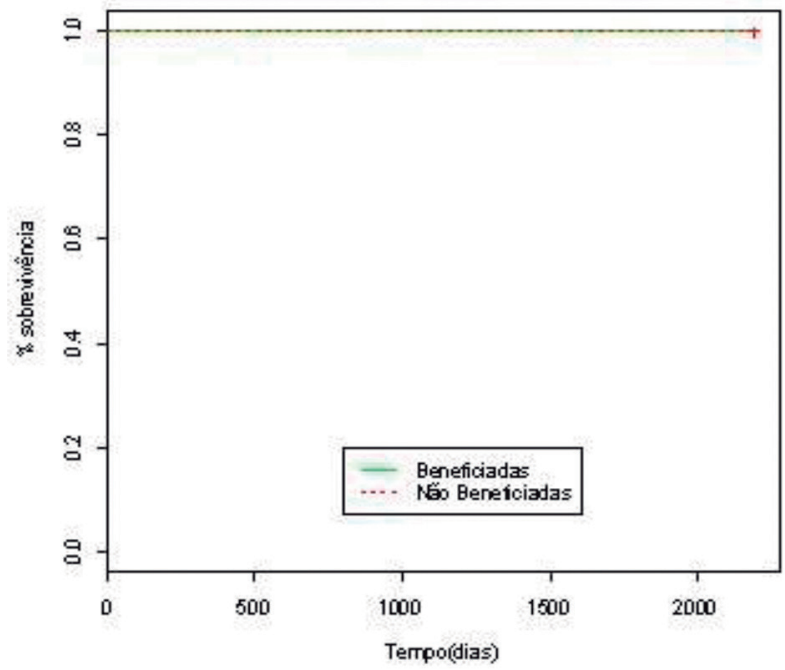

Elaboração do autor.

Obs.: Figura reproduzida em baixa resolução e cujos leiaute e textos não puderam ser padronizados e revisados em virtude das condições técnicas dos originais (nota do Editorial).

GRÁFICO A.10

\section{Móveis e colchões}

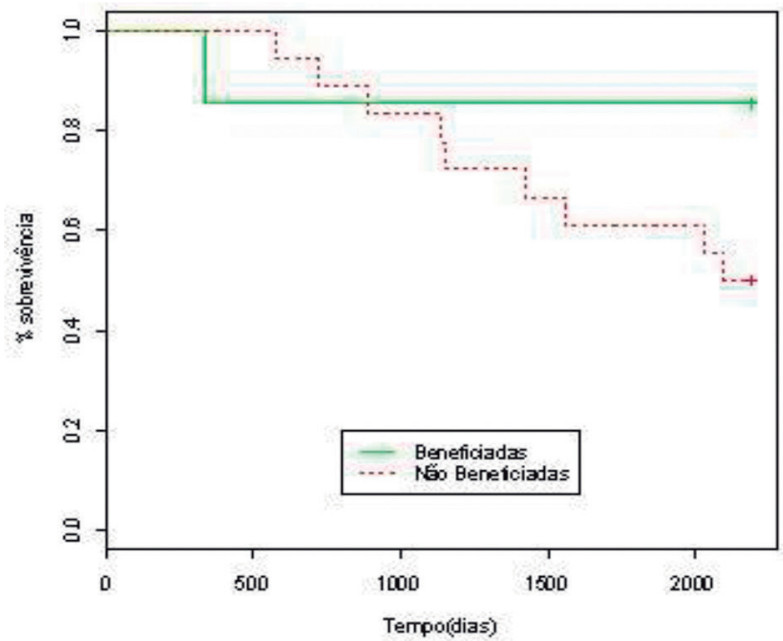

Elaboração do autor.

Obs.: Figura reproduzida em baixa resolução e cujos leiaute e textos não puderam ser padronizados e revisados em virtude das condições técnicas dos originais (nota do Editorial). 
GRÁFICO A.11

Outros segmentos

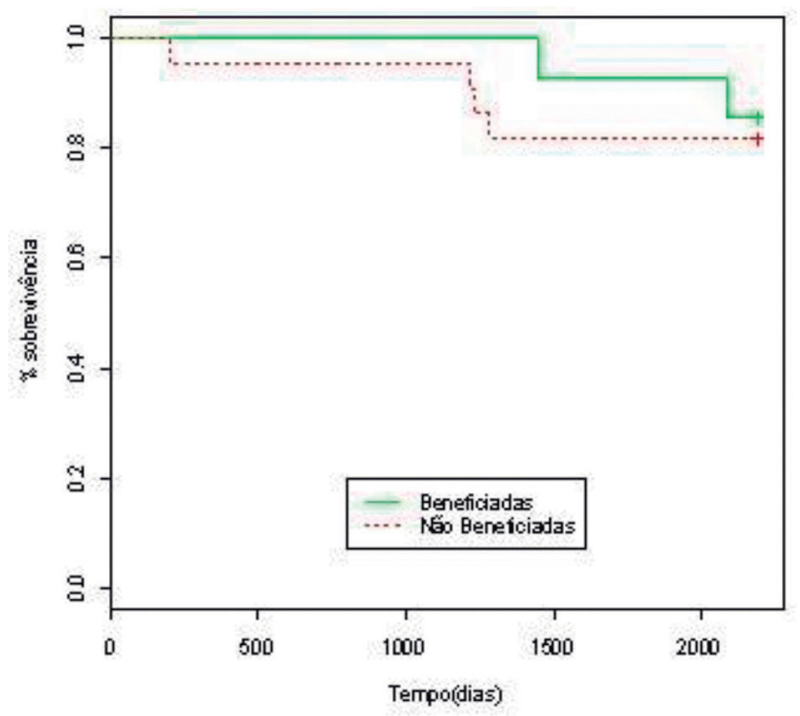

Elaboração do autor.

Obs.: Figura reproduzida em baixa resolução e cujos leiaute e textos não puderam ser padronizados e revisados em virtude das condições técnicas dos originais (nota do Editorial).

Data da submissão: 15/9/2017

Primeira decisão editorial em: 18/7/2018

Última versão recebida em: 11/10/2018

Aprovação final em: 19/10/2018 